\title{
10 Characterization of Sugar Palm Nanocellulose and Its Potential for Reinforcement with a Starch-Based Composite
}

R.A. Ilyas

Universiti Putra Malaysia

S.M. Sapuan

Universiti Putra Malaysia

M.R. Ishak

Universiti Putra Malaysia

E.S. Zainudin

Universiti Putra Malaysia

M.S.N. Atikah

Universiti Putra Malaysia

\section{CONTENTS}

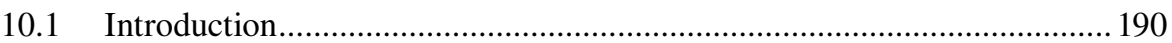

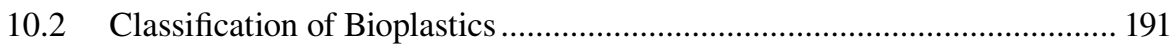

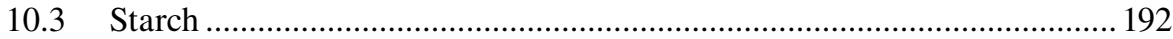

10.3.1 Sugar Palm Starch (SPS) ............................................................ 192

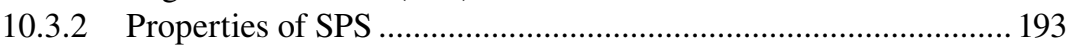

$10.4 \quad$ Nanocrystalline Cellulose (NCC) ............................................................ 194

10.4.1 Morphological Analysis of Sugar Palm Fibers, Treated

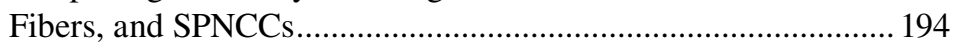

10.4.2 Sugar Palm NCC Characterization .............................................. 196

10.5 Nanofibrillated Cellulose (NFC) ………………..................................... 200

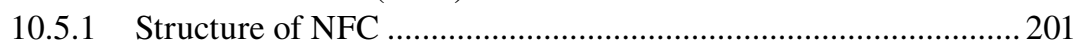

10.6 Extraction of Sugar Palm NFC ...............................................................2202

10.7 Nanocellulose-Reinforced Starch-Based Composites ................................205 
10.8 SPNCC-Reinforced SPS Biopolymers .................................................206

10.9 Nanocellulose in Antimicrobial Food-Packaging Materials ..................... 211

Conclusions ............................................................................................ 212

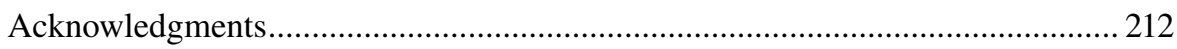

\subsection{INTRODUCTION}

Mankind has gained many benefits from the development of products derived from petroleum-based polymers, and one important area of benefit is in food-packaging applications. However, petroleum-based polymers have caused serious environmental problems for the global ecosystem due to their non-renewability and nonbiodegradability as they are discarded (Cao et al., 2008b). Therefore, to overcome these problems, non-biodegradable packaging waste materials have to be reduced by shifting to eco-friendly packaging while maintaining food quality and stability.

Starches including sugar palm starch (SPS) are considered as promising substitute polymers due to their "green" footprint, and there is huge potential for the products that could be made from these materials, such as flushable liners, shopping bags, food- and fruit-packaging films, as well as medical delivery devices and systems (Ilyas et al., 2016; French and Murphy, 1976; Rhim 2007; Kelfkens and Hamer 1991; Fishman et al., 2000; Jumaidin et al., 2017a,b). In 2014, the global biodegradable polymer market was valued at approximately 1.68 billion USD, and in 2020 it is predicted to rise to approximately 5.18 billion USD. The use of bio-based polymers from renewable resources (such as SPS) has gained much interest recently among researchers, nevertheless, the utilization of these green materials, especially in food-packaging applications, is greatly restricted by their rigidity, poor water sensitivity, low mechanical strength, and brittleness (Sanyang et al., 2015a). To overcome these problems, the incorporation of reinforcing structures such as lignin (Lepifre et al., 2004), clay (Chen and Evans, 2005), cellulose (Sanyang et al., 2016c), sugar palm fiber (Sahari et al., 2012), multi-walled carbon nanotubes (Cao et al., 2007), and sugar palm nanocellulose (Ilyas et al., 2018) with these thermoplastic polymers may enhance their properties.

Cellulose nanostructures can be categorized into three types: nanocrystalline cellulose (NCC), nanofibrillated cellulose (NFC), and bacterial nanocellulose (BNC). NCC and NFC can be isolated through plant-based materials, whereas BNC is produced by the bacteria Gluconacetobacter xylinus. NCC has a needlelike crystalline appearance, and it measures $100-1,000 \mathrm{~nm}$ in length and 4-25 $\mathrm{nm}$ in diameter (Ilyas et al., 2016; Ilyas, et al., 2017b; Ilyas et al., 2018). NCC is often produced through chemical or chemomechanical processes. NFC is also known as cellulose microfibril and is composed of an alternating structure of amorphous parts and crystalline parts with a length of several micrometers and a diameter of $10-100 \mathrm{~nm}$. NFC is usually isolated with a mechanical process (Jonoobi et al., 2015). The synthesis of BNC occurs between the outer and plasma membranes of the bacterial cell by a cellulosesynthesizing complex, starting with biochemically activated dextrose. BNC has a diameter of $\sim 3 \mathrm{~nm}$ (Gatenholm and Klemm, 2010). This chapter aims to review the outcomes and potential applications of sugar palm nanocellulose- reinforced starch for green-based food-packaging and food-coating purposes. 


\subsection{CLASSIFICATION OF BIOPLASTICS}

Many people use the terms "bioplastic" and "biodegradable plastic" interchangeably, but this is incorrect because bioplastic is made only from renewable materials, whereas biodegradable plastic is made of either fossil-based polymer or a combination of both materials (Reddy et al., 2013) (Figure 10.1).

Bioplastics are classified based on their production routes.

1. Petroleum-based bioplastics, including poly(butylene adipate-coterephthalate), polycaprolactone, and polyvinyl alcohol, are produced from petroleum resources, although they are biodegradable in nature.

2. Polylactic acid is a transparent plastic obtained by either direct polycondensation of lactic acid or by ring-opening polymerization of lactide.

3. Polyhydroxyalkanoates are the family of biopolyesters produced in nature by bacterial/microorganism fermentation of lipids or sugar. They are obtained when bacteria are exposed to a carbon source when other necessary nutrients become limited.

4. Starches include both branched and linear polysaccharides known as amylopectin and amylose, respectively. Plasticizers such as water, glycerin, and sorbitol are added to increase the free volume, thus decreasing the softening and glass transition temperatures. Both polysaccharides vary in their botanical origin. They can be obtained via corn, wheat, potatoes, sugar palm, and other plants.

5. Cellulose is an abundant and ubiquitous natural polymer obtained from fibers, cotton, and wood, as well as from non-plant resources such as bacteria and tunicates. Cellulose pulp is extracted from agricultural

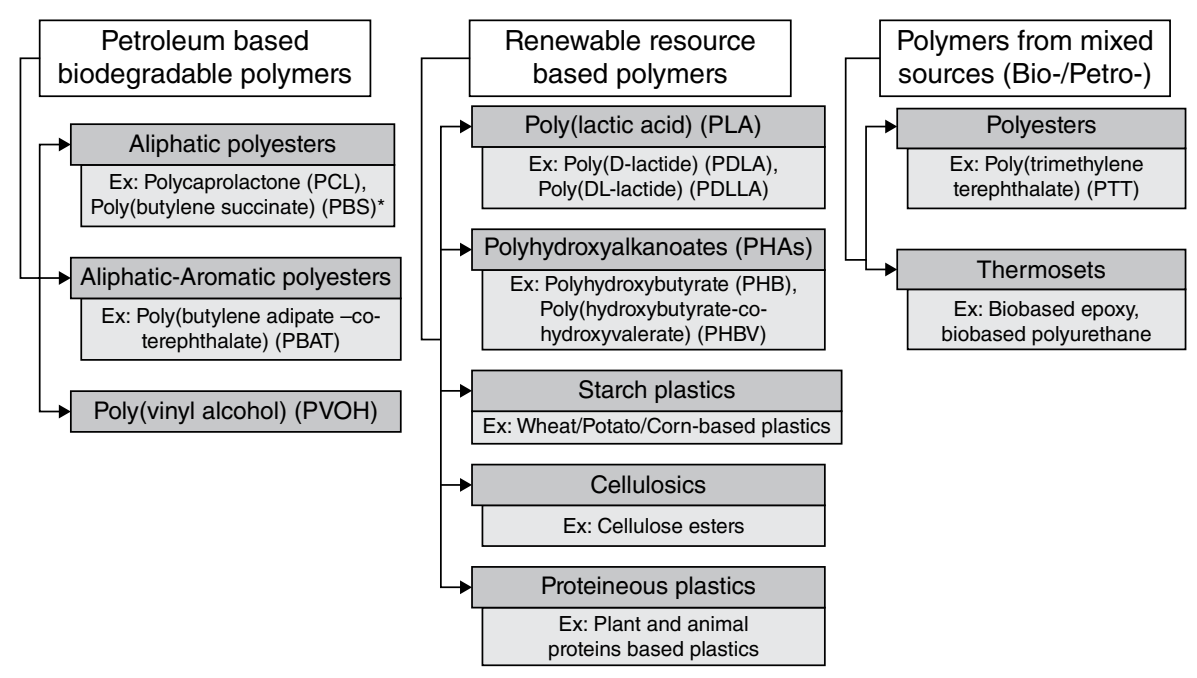

FIGURE 10.1 Classification of bioplastics based on their production routes. (Reddy et al., 2013.) 
by-products such as stalks, sugar palm fibers (Ilyas et al., 2017b), crop straws, and bagasse. Cellulose bioplastics are mainly composed of cellulose esters, which include nitrocellulose and cellulose acetate and their derivatives, including celluloid.

6. Protein plastic is produced from proteins that are random copolymers of different amino acids. Protein plastics can be classified based on their origin, such as animal proteins (e.g., gelatin, casein, whey, keratin) and plant proteins (e.g., wheat, canola, pea, soy protein). Fatty acids, water, oils, and glycerols are generally used as plasticizers for protein plastics.

7. Bioplastics from mixed sources are derived from the incorporation of petroleum- and bio-based monomers (e.g., polytrimethylene terephthalate), which are synthesized using petroleum-derived terephthalic acid and biologically derived 1,3-propanediol.

\subsection{STARCH}

The disadvantages of conventional synthetic plastic materials, which are resistant to biodegradation and microbial attack, have led many scientists to study the development and characteristics of biopolymers. Starch is considered one of the most promising polymers among all biopolymers due to its complete biodegradability, availability, renewability, and lower cost of production. In addition, the development of starch could provide renewable polymer composites options to the next generation of plastic designers.

Starch that functions to store polysaccharides or carbohydrates in plants such as the sugar palm, wheat, rice, potatoes, and corn is already used widely as a bioplastic (Sanyang et al., 2016a,b,c; Sanyang et al., 2015b). In addition, starches are hydrophilic polymers that naturally exist in nature in the form of partially and discrete crystalline microscopic granules bonded by an extended micellar network of combined molecules. Starch is composed of both branched and linear polysaccharides, known as amylopectin and amylose, respectively, and they vary according to their botanical origin. In most cases, native starch contains $70-85 \%$ amylopectin and 15-30\% amylose (Reddy et al., 2013). The processing of starch is affected by the existence of many intermolecular hydrogen bonds, which result in higher starch softening temperatures than its degradation temperature (Halley, 2005). Therefore, plasticizers such as glycerol, water, and sorbitol are used to facilitate the increase of the free volume and hence decrease the softening and glass transition temperatures (Coffin and Fishman, 1994). Thermoplastic starch (TPS) is formed when there is disruption of the starch molecular structure, where heating of starch granules caused swelling and a non-irreversible transition of amorphous regions in the presence of a plasticizer under specific condition (Avérous, 2004).

\subsubsection{Sugar Palm Starch (SPS)}

Commercially used industrial starches commonly come from tubers (e.g., potatoes, sweet potatoes) cereals (e.g., rice, wheat), roots (e.g., cassava, yams), and legumes (e.g., green peas, beans). However, these are food staple sources for many 
poor countries where the consumption of such biomaterial in composite materials has been criticized. To overcome these problems, extensive research has been conducted to shift the use of food sources to non-food sources for polymeric matrix to develop biopolymer. One of them is SPS, which is located in the core of the sugar palm tree's trunk. The average yield of each sugar palm tree is $50-100 \mathrm{~kg}$. Sugar palm trees are cultivated for the most part to harvest their fibers and the sugarrich sap from its flower. Sanyang et al. (2016c) reported that not all sugar palms produce sap, and that the non-productive plants sometimes comprise half of the trees in the cultivated area. Starch is usually extracted from these unproductive trees following a process similar to that for producing sago starch (Sanyang et al., 2016c). The white powdered starch is then dried in an air-circulating oven at $120^{\circ} \mathrm{C}$ for 24 hours (Sahari et al., 2013).

\subsubsection{Properties of SPS}

Sahari et al. (2013) studied the properties of SPS to determine their potential as a novel alternative polymer. SPS has good potential to be used as an alternative polymer due to its superior amylose content $(37.60 \%)$ compared to other starches such as maize (26-28\%), potatoes (20-25\%), tapioca (17\%), wheat (26-27\%), and sago (24-27\%). Amylopectin is defined as a branched polysaccharide component of starch made up of hundreds of short chains formed of $\alpha$-D-glucopyranosyl residue with $(1 \rightarrow 4)$ linkages. These are interlinked by $(1 \rightarrow 6)$ - $\alpha$-linkages, $5-6 \%$ of which occur at the branch points. SPS has high amylopectin with high molecular weight $\left(10^{7}-10^{9}\right)$, but it has low intrinsic viscosity $(120-190 \mathrm{~mL} / \mathrm{g})$ due to its extensively branched molecular structure. SPS also has low fat and protein content of $0.27 \%$ and $0.10 \%(\mathrm{w} / \mathrm{w})$, respectively. In terms of density, SPS has a high density $\left(1.54 \mathrm{~g} / \mathrm{cm}^{3}\right)$ compared to other biopolymers (Table 10.1). SPS also has a high moisture content of $15 \%$ under normal atmospheric conditions, which is due to the presence of hydroxyl functional groups as shown by the strong peak at 3,200-3,500/cm on Fourier-transform infrared spectroscopy (FT-IR) analysis. The ash content for SPS is lower than that of potatoes $(0.4 \%)$, being similar to that of wheat, tapioca, and sago $(0.2 \%)$.

\section{TABLE 10.1}

\section{Chemical Composition of Commercial Starches and Sugar Palm Starch}

\begin{tabular}{lcccc} 
Starch & Density & Ash (\%) & Amylose (\%) & Water Content (\%) \\
Wheat & 1.44 & 0.2 & $26-27$ & 13 \\
Tapioca & $1.446-1.461$ & 0.2 & 17 & 13 \\
Maize & 1.5 & 0.1 & $26-28$ & $12-13$ \\
Potato & $1.54-1.55$ & 0.4 & $20-25$ & $18-19$ \\
Sago & - & 0.2 & $24-27$ & $10-20$ \\
Sugar palm starch & 1.54 & 0.2 & 37.60 & 15 \\
From Sanyang et al., 2016c & & & & \\
\hline
\end{tabular}




\subsection{NANOCRYSTALLINE CELLULOSE (NCC)}

Nanocrystalline cellulose is defined as a set of cellulose particles that have at least one dimension (diameter, length, or thickness) that less than $100 \mathrm{~nm}$. NCCs have attracted a tremendous of interest in material science due to their appealing intrinsic properties, including nanodimension, high surface area $\left(100 \mathrm{~m}^{2} / \mathrm{g}\right)($ Savadekar and Mhaske 2012; Silvério et al., 2013; Islam, 2013), high aspect ratio of 100 (Tee et al., 2013; Savadekar and Mhaske, 2012; Rosa et al., 2010), high crystallinity, low density, high mechanical strength, unique morphology, availability, renewability, and biodegradability (Azizi et al., 2005; $\mathrm{Ng}$ et al., 2015). According to Cao et al. (2011), the theoretical value of Young's modulus of pure NCC domain is approximately $150 \mathrm{GPa}$, a value that, for comparison, approached the value of steel, $200 \mathrm{GPa}$. Moreover, NCCs can be produced from various plant sources (such as sugar palm fiber), by means of polydisperse dimensions distribution as small as 5-70 $\mathrm{nm}$ in diameter and 100-250 $\mathrm{nm}$ in length, giving a high surface to volume ratio (Eichhorn, 2011; Klemm et al., 2011). Despite its abundant sources, nanocellulose also has abundant hydroxyl groups that are present on the surface of NCCs. To induce the reinforcing effect in polymers, these hydroxyl groups provide active sites for hydrogen bonding through physical interlocking with the non-polar matrices and the $-\mathrm{OH}$ groups of hydrophilic polymer matrices (Minelli et al., 2010; Majeed et al., 2013; Sundari et., 2012). Therefore, because starch possesses hydrophilic properties, NCCs are very suitable to be used as a material reinforced with starch.

\subsubsection{Morphological Analysis of Sugar Palm Fibers, Treated Fibers, aNd SPNCCS}

Ilyas et al. (2018) prepared NCCs from raw sugar palm fiber via delignification, mercerization, and acid hydrolysis methods. They reported that the bleaching and alkali treatments not resulted only in changes of chemical composition of the treated fibers, but also in changes in the structure of the fiber surfaces. Figure 10.2 shows the sugar palm tree and its fibers at different stages of treatment. The sugar palm fibers changed color from black (Figure 10.2d) to light brown after bleaching treatment (delignification) (Figure 10.2e) and became white after alkali treatment (mercerization) (Figure 10.2f). A field emission scanning electron microscope revealed the homogeneity and micrometric dimensions of the sugar palm fibers. Microscopic examination of the longitudinal view and cross-section of sugar palm fibers are depicted in Figure 10.2b,c,g. Figure 10.2g shows sugar palm fibers (approximate diameter sizes of $212.01 \pm 2.17 \mu \mathrm{m}$ ) that in the original form were bonded by cement components known as middle lamella, which were partially removed after the bleaching treatment (Figure 10.2h). These images also show the partial removal of impurities such as pectin, lignin, and hemicellulose after chemical treatment, which acted as cementing components around fiber bundles.

Figure $10.2 \mathrm{~b}$ and $10.2 \mathrm{c}$ show the view from the outer to the inner part and demonstrate that sugar palm fibers consist of a middle lamella $(1.98 \pm 0.15 \mu \mathrm{m})$, a primary cell wall $(10.38 \pm 0.57 \mu \mathrm{m})$, a secondary cell wall, and a tertiary cell wall, built up around the lumen $(3.72 \pm 0.15 \mu \mathrm{m})$. Figure $10.2 \mathrm{~g}$ shows that the longitudinal section 


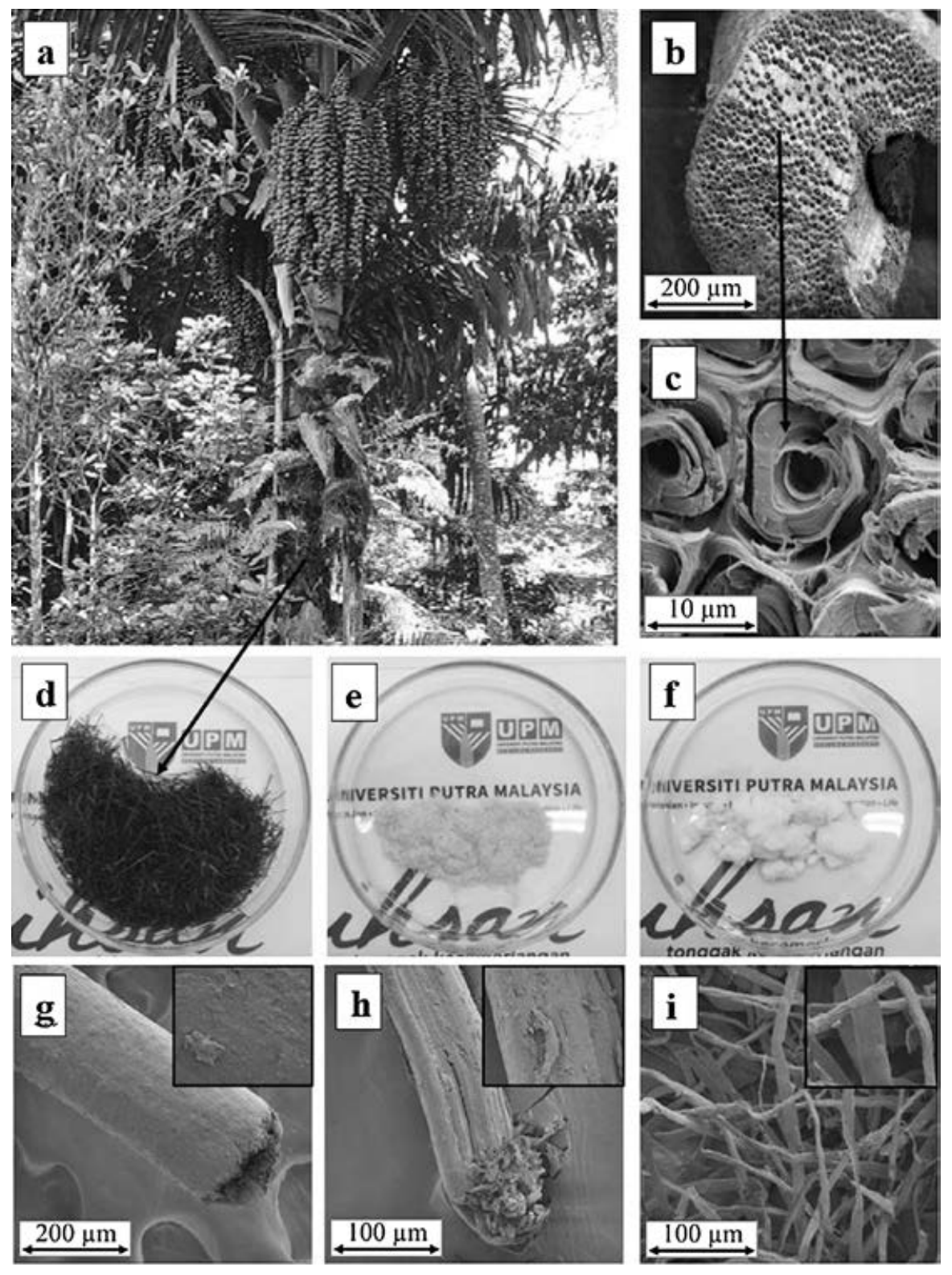

FIGURE 10.2 Photographs of (a) the sugar palm tree, (d) raw sugar palm fibers, (e) bleached fibers and (f) alkali-treated fibers. Field emission scanning electron microscope images of sugar plant fibers: (g) cross section, (b) longitudinal section, (c) primary, secondary cell wall, and middle lamella, (h) alkali-treated fibers, (i) and bleached fibers. (Ilyas et al., 2018.) 
of sugar palm fiber surface topography is rough, with pore-like spots that appear in almost regular intervals; similar spots were found on the surface of coir fibers (Ticoalu et al., 2013). These pore-like spots are known as tyloses, and their function is to cover the pits on the cell walls.

In addition, based on the observations of sugar palm fiber microstructure, there is strong evidence that the acid-bleaching treatment $\left(\mathrm{NaClO}_{2}\right)$ transformed the physical surface appearance of sugar palm fibers compared to raw sugar palm fibers (Figure 10.2a,h) (Ilyas et al. 2018). A drastic physical change with slight fibrillation was clearly observed on the outer surface of the fibers where the outer surface became clear, and this was due to the elimination of the waxy layer on the outer surface. The average diameter of the fibers was reduced after the bleaching treatment from $212.01 \pm 2.17 \mu \mathrm{m}$ to $121.80 \pm 10.57 \mu \mathrm{m}$. These were measured after the partial removal of lignin and hemicelluloses. Moreover, the bleaching treatment removed the extractives from the fibers, as indicated by the surface changes. After alkali treatment (Figure 10.2i), the fiber bundles where dispersed into individual fibers with diameters in the range $11.87 \pm 1.04 \mu \mathrm{m}$. Bleached fibers and alkali-treated fibers were almost double and eighteen times smaller than raw sugar palm fibers, respectively. The removal of lignin and hemicellulose through the process of delignification and mercerization of raw sugar palm fibers caused drastic reductions in the diameter of the fibers, and the surface of SPC (Figure 10.2i) changed to a smooth surface with parallel grooves arranged along the cellulose. The diameter of SPC obtained is similar to the average diameter of kenaf-derived cellulose $(13 \mu \mathrm{m})$ and cellulose microfibers reported by Sonia et al. (2013) and Tawakkal et al. (2012), respectively. The chemical treatments used on the fibers also affected the characterization of the separation of micro-sized fibers from the fiber bundles into individual micro-sized fibers.

\subsubsection{Sugar Palm NCC Characterization}

Sugar palm NCCs (SPNCCs) can be extracted from sugar palm cellulose via acid hydrolysis treatment using concentrated sulfuric acid. Acid hydrolysis is a well-known treatment used to remove amorphous region. Several studies have been reported where NCCs were identified and separated from the sugar palm bunch (Sumaiyah et al., 2014) and from sugar palm fibers (Fahma et al. 2016; Ilyas et al., 2018).

Sumaiyah et al. (2014) also prepared NCCs from $\alpha$-cellulose of sugar palm bunch via hydrolysis using concentrated sulfuric acid (54\%) (Figure 10.3). Transmission electron microscope (TEM) images of NCCs displayed nanosize dimension with a diameter of 15-20 nm and a spherical shape. The analysis of functional groups showed that sulfuric acid did not change the functional group of cellulose, but only removed the chain of cellulose. FT-IR analysis also showed the presence of $\mathrm{OH}$ groups, alkane $\mathrm{CH}$, $\mathrm{OH}$ from water absorption, and $\mathrm{CO}$ (glycosidic bond) between glucose units in cellulose. The structure and degree of crystallinity of NCCs from sugar palm bunch was 97.57\%, whereas thermal gravimetric analysis (TGA) showed that the first mass loss occurred at temperature of $173^{\circ} \mathrm{C}$ with a residual mass of $11.25 \%$. The NCCs degrade at low temperature due to the presence of sulfate groups on the cellulose. In addition, the size of the NCCs contribute more free chain ends, thus the end chain starts to decompose at a lower temperature and increases the char yield of this NCC sample. 

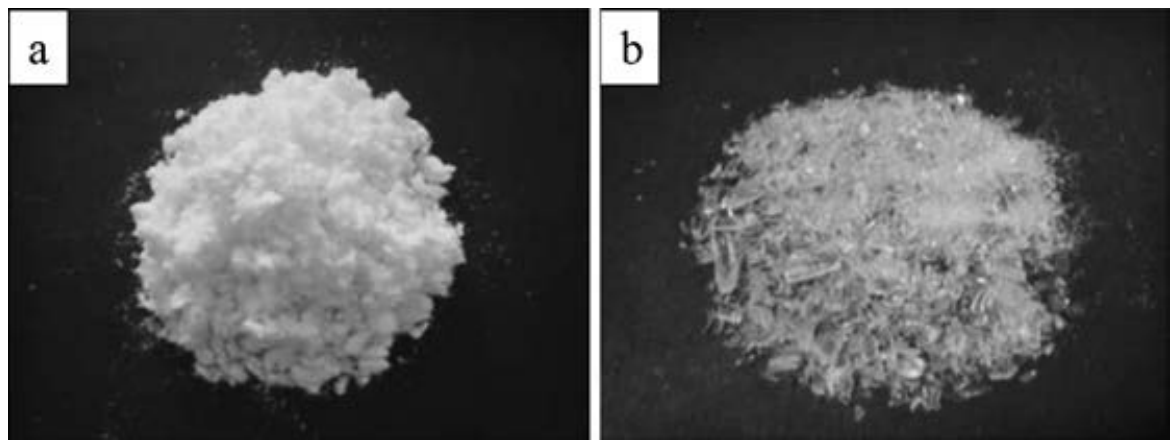

FIGURE 10.3 $\alpha$-cellulose (a) and nanocrystalline cellulose (b) of sugar palm bunch. (Sumaiyah et al., 2014.)

Ilyas et al. (2018) prepared NCCs from $\alpha$-cellulose of sugar palm fiber via acid hydrolysis using concentrated sulfuric acid $(60 \mathrm{wt} \%)$ for different amounts of time (30 min, $45 \mathrm{~min}$, and $60 \mathrm{~min}$, denoted as SPNCCs-30, SPNCCs-45, and SPNCCs-60, respectively) (Figure 10.4). TEM nanographs of SPNCCs (Figure 10.4) revealed their nanometric dimension. The resultant suspension of isolated SPNCCs prepared from
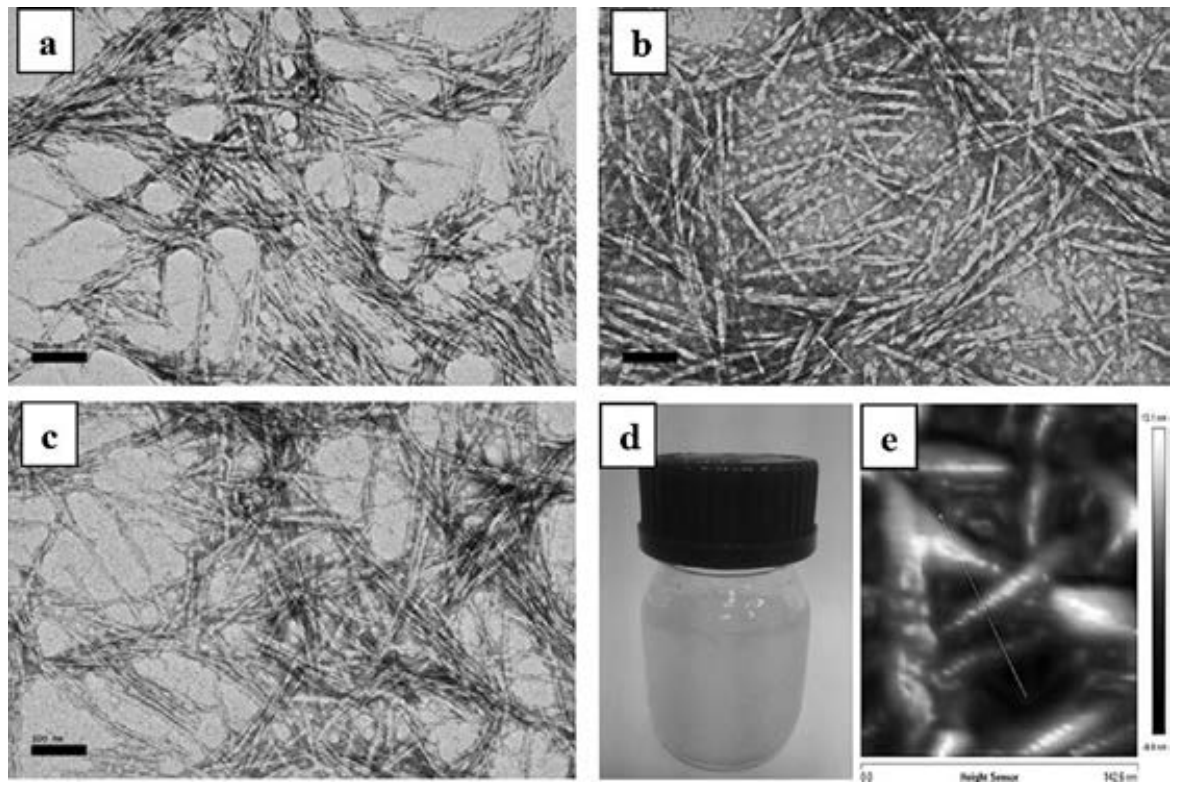

FIGURE 10.4 Transmission electron microscope micrographs of (a) SPNCCs-30, (b) SPNCCs-45, (c) SPNCCs-60, (d) aqueous suspension (2 wt\%) of SPNCCs, and (e) atomic force microscopy image of SPNCCs-45. (Ilyas et al., 2018.) 


\section{TABLE 10.2}

\section{Physical Properties of SPNCCs-30, SPNCCs-45, and SPNCCs-60}

\section{Fibers}

Sugar palm cellulose

SPNCCs-30

SPNCCs-45

SPNCCs-60
Length (nm)

$175 \pm 37.01$

$130 \pm 30.23$

$110 \pm 33.69$
Diameter (nm)

11,870

$13 \pm 1.73$

$9 \pm 1.96$

$7.5 \pm 1.35$

SPNCC: sugar palm nanocrystalline cellulose.

From Ilyas et al., 2017b

cellulose sugar palm fiber is shown in Figure 10.4d. The concentration of this suspension was $2 \mathrm{wt} \%$. The average length of the SPNCCs-30, SPNCCs-45, and SPNCCs-60 were $175 \pm 37.01 \mathrm{~nm}, 130 \pm 30.23 \mathrm{~nm}$, and $110 \pm 33.69$, respectively, and the diameter of the SPNCCs-30, SPNCCs-45, and SPNCCs-60 were approximately $13 \pm 1.73 \mathrm{~nm}$, $9 \pm 1.96 \mathrm{~nm}$, and $7.5 \pm 1.35 \mathrm{~nm}$, respectively (Table 10.2). These diameters were similar to those for nanosized structures extracted from other agro-waste sources such as coconut husk $(5.5 \pm 1.5 \mathrm{~nm}$ ) (Rosa et al., 2010), rice straw $(5.06 \mathrm{~nm}$ ) (Sundari and Ramesh, 2012), soy hulls ( $4.43 \pm 1.20 \mathrm{~nm}$ ) (Flauzino et al., 2013), sugarcane bagasse $(4 \pm 2 \mathrm{~nm})$ (Teixeira et al., 2011a), and banana residues (5nm) (Zuluaga et al., 2007), and they were smaller than microfibrils from wheat straw (10-80 nm) (Alemdar and Sain, 2008), sisal fibers $(30.9 \pm 12.5 \mathrm{~nm})$ (Morán et al., 2008), and sugarcane bagasse (30nm) (Bhattacharya et al., 2008). The resultant images (Figure 10.4) revealed that the aqueous suspensions contained SPNCCs consisting mostly of individual crystals and some aggregates. The differences between the SPNCCs-30, SPNCCs-45, and SPNCCs-60 were in the reduction of length and diameter (e.g., the reduction of SPNCCs-30 compared to SPC was 99.89\%) (Table 10.2).

Ilyas et al. (2017a) attributed these reductions to the removal of the amorphous region via the hydrolysis treatment on SPC. The hydrolysis continued for the SPNCCs-45 and SPNCCs-60 for 45 minutes and 60 minutes, respectively, and resulted in reductions in the size of the SPNCCs of $31 \%$ and $42 \%$, respectively, compared to SPNCCs-30, respectively. This was caused by the longer reaction time of $\mathrm{H}_{2} \mathrm{SO}_{4}$ via hydrolysis treatment on the fibers, which removed amorphous region from the nanofibers. Longer hydrolysis times could also irritate the structure (length and diameter) of SPNCCs. Thus, the longer the reaction times of hydrolysis, the smaller the length and diameter of the nanofibers. Atomic force microscopy phase images (Figure 10.4e) revealed a peak nanofiber height of $5.781 \mathrm{~nm}$, which is comparable to the average nanofiber diameter $(10.7 \pm 2.34 \mathrm{~nm})$ determined from the atomic force microscopy images. Thermogravimetric analysis data obtained from raw sugar palm fibers, bleached fibers, alkali fibers, and hydrolysis treatment are shown in Table 10.3 (Ilyas et al., 2018).

According to Ilyas et al. (2018), the initial weight loss that started around $42^{\circ} \mathrm{C}$ was caused by water evaporation in these samples. As the fibers are heated, there 
TABLE 10.3 $\mathrm{T}_{\text {onset, }} \mathrm{T}_{\max }, \mathrm{W}_{\mathrm{L}}$, and Char Yield for Raw Sugar Palm Fibers, Bleached Fibers,
Alkali-Treated Fibers and SPNCCs Obtained from the TGA and DTG Curves

\begin{tabular}{|c|c|c|c|c|c|c|c|c|c|c|}
\hline \multirow[t]{2}{*}{ Sample } & \multicolumn{3}{|c|}{ Water Evaporation } & \multicolumn{3}{|c|}{$\begin{array}{l}\text { First Thermal } \\
\text { Degradation }\end{array}$} & \multicolumn{3}{|c|}{$\begin{array}{l}\text { Second Thermal } \\
\text { Degradation }\end{array}$} & \multirow{2}{*}{$\begin{array}{c}\text { Char } \\
\text { Yield } \\
\text { W } \\
(\%)\end{array}$} \\
\hline & $\begin{array}{l}\mathrm{T}_{\text {onset }} \\
\left({ }^{\circ} \mathrm{C}\right)\end{array}$ & $\begin{array}{l}T_{\max } \\
\left({ }^{\circ} \mathrm{C}\right)\end{array}$ & $\begin{array}{l}W_{\mathrm{L}} \\
(\%)\end{array}$ & $\begin{array}{l}\mathrm{T}_{\text {onset }} \\
\left({ }^{\circ} \mathrm{C}\right)\end{array}$ & $\begin{array}{l}\mathrm{T}_{\max } \\
\left({ }^{\circ} \mathrm{C}\right)\end{array}$ & $\begin{array}{l}W_{\mathrm{L}} \\
(\%)\end{array}$ & $\begin{array}{l}\mathrm{T}_{\text {onset }} \\
\left({ }^{\circ} \mathrm{C}\right)\end{array}$ & $\begin{array}{l}T_{\max } \\
\left({ }^{\circ} \mathrm{C}\right)\end{array}$ & $\begin{array}{l}W_{\mathrm{L}} \\
(\%)\end{array}$ & \\
\hline Raw sugar palm fibers & 41.73 & 106.78 & 10.38 & 210.58 & 281.00 & 15.13 & 308.05 & 345.45 & 43.76 & 30.73 \\
\hline Bleached fibers & 42.37 & 103.74 & 9.87 & 195.66 & 271.56 & 15.24 & 288.35 & 324.44 & 52.39 & 22.50 \\
\hline Alkali-treated fibers & 43.49 & 101.23 & 8.58 & 207.92 & 346.09 & 73.41 & - & - & - & 17.71 \\
\hline SPNCCs & 43.72 & 103.43 & 7.37 & 185.78 & 348.65 & 78.41 & - & - & - & 17.97 \\
\hline \multicolumn{11}{|c|}{$\begin{array}{l}\mathrm{T}_{\text {onset }} \text { : onset temperature; } \mathrm{T}_{\max } \text { : degradation temperature on maximum weight-loss rate; } \mathrm{W}_{\mathrm{L}} \text { : weight loss; } \\
\text { SPNCC: sugar palm nanocrystalline cellulose; TG: thermal gravimetric analysis; DTG: differential ther- } \\
\text { mal gravimetric analysis. } \\
\text { From Ilyas et al., } 2018\end{array}$} \\
\hline
\end{tabular}

was an initial reduction in the weight of the material due to the loss of water and volatile extractive, which tend to move to the surface of fibers (Rosa et al., 2010). The raw sugar palm fibers displayed an earlier weight loss starting at $210.58^{\circ} \mathrm{C}$, which then peaked at $281^{\circ} \mathrm{C}$, due to the low decomposition temperature of hemicellulose and lignin (Morán et al., 2008). The cellulose fibers obtained with the bleaching treatment showed a higher decomposition temperature around $345^{\circ} \mathrm{C}$. Moreover, the SPNCCs displayed their first thermal degradation at $\mathrm{T}_{\text {Onset }}=$ $185.78^{\circ} \mathrm{C}$ and $\mathrm{T}_{\text {Max }}=348.65^{\circ} \mathrm{C}$. This indicates that the higher the crystalline structure, the higher the degradation temperature (Cherian et al., 2008). The higher crystallinity of the fiber structure indirectly enabled the fiber to endure severe heat and processing conditions. Therefore, it can be concluded that the production of SPNCCs displayed an enhancement of thermal properties of fibers compared to untreated fibers, which indicates that they are suitable as reinforcing materials in bio-renewable composite materials.

Fahma et al. (2016) prepared NCCs from $\alpha$-cellulose of sugar palm fibers via acid hydrolysis using a sulfuric acid solution (64 wt \%) under strong agitation at $45^{\circ} \mathrm{C}$ for 90 minutes. From the atomic force microscopy image of NCCs in Figure 10.5, the nanosized dimensions of un-neutralized and neutralized NCCs of sugar palm fiber were not significantly different with diameters of $2.3 \pm 0.9 \mathrm{~nm}$ and $2.4 \pm 0.8$ $\mathrm{nm}$, respectively. The small amount of $\mathrm{NaOH}$ that was added resulted in no change on the NCC morphology. The atomic force microscopy image also shows that the NCCs are mostly in the form of individual nanofibrils, indicating that the hydrolysis treatment using $\mathrm{H}_{2} \mathrm{SO}_{4}$ was effective. An x-ray powder diffraction analysis was used to determine the crystalline structure of samples. Both un-neutralized and neutralized NCCs had similar cellulose I crystal structures, which indicate that the addition of $\mathrm{NaOH}$ into $\mathrm{NCCs}$ until the $\mathrm{pH}$ turned neutral did not change the structure 

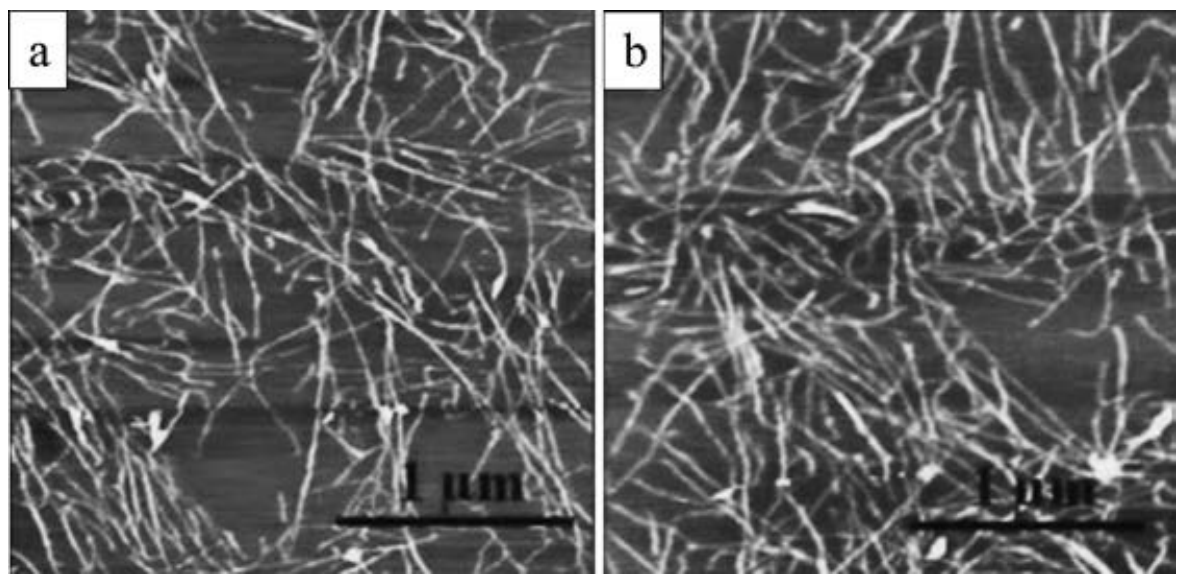

FIGURE 10.5 Atomic force microscopy images of un-neutralized (a) and neutralized (b) NCCs of sugar palm fiber. (Fahma et al., 2016.)

of the NCCs. However, the degree of crystallinity and the size of cellulose crystals decreased after sulfuric acid hydrolysis of untreated NCC from $54.84 \%$ to $54.56 \%$ and from $3.12 \mathrm{~nm}$ to $2.57 \mathrm{~nm}$, respectively, due to the drastic effects of sulfuric acid treatment that destroyed the amorphous region as well as the crystalline regions. The un-neutralized NCCs also had two separate pyrolysis processes; the first pyrolysis started to degrade at $150-280^{\circ} \mathrm{C}$, and the second pyrolysis occurred at $300-500^{\circ} \mathrm{C}$, which is earlier than for cellulose and neutralized NCCs. The first degradation process might due to the attachment of acid sulfate group on the NCCs, and the second degradation process might due to the NCCs that are unattached to the acid sulfate group. However, the neutralized NCCs showed only one pyrolysis process, at a degradation temperature of $300^{\circ} \mathrm{C}$, which indicates that the attachment of acid sulfate groups on NCCs caused a significant decrease in thermal stability. FT-IR analysis also confirmed the similarities in the chemical composition of un-neutralized and neutralized NCCs.

\subsection{NANOFIBRILLATED CELLULOSE (NFC)}

Cellulose (like sugar palm cellulose) is composed of linear chains of ringed glucose molecules with a flat, ribbon-like structure. Two anhydroglucose rings $\left(\mathrm{CH}_{6} \mathrm{H}_{10} \mathrm{O}_{5}\right)_{n}$ consolidate to form a replication unit (Figure 10.6a), where $n=10,000$ to 15,000, depending on the source of material. These two anhydroglucose rings are linked together through the $\beta$ 1-4 glycosidic bond, in which oxygen covalently bonds to $\mathrm{C} 1$ of one glucose ring and to $\mathrm{C} 4$ of the adjoining ring $(1 \rightarrow 4$ linkage).

Moreover, the interchain hydrogen bonding of oxygen with the adjoining ring molecules $(\mathrm{O} \rightarrow \mathrm{C} 4)$ and hydroxyl groups result in the linkage stabilization and the linear configuration of the cellulose chain. During the biosynthesis process, microfibrils with diameters of 5-50 $\mathrm{nm}$ and lengths of several microns were formed 


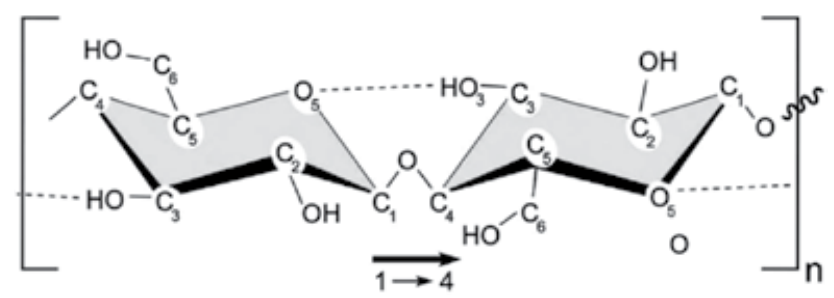

(a)

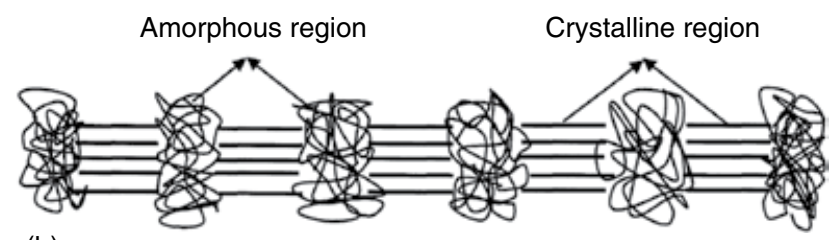

(b)

FIGURE 10.6 Schematic of (a) single cellulose chain replication unit and (b) structure of crystalline and amorphous region. (Moon et al., 2011.)

from the aggregation of elementary fibrils of cellulose chains. These intra- and inter-chains of the hydrogen bonding network promote the high axial stiffness and stable ploymer observed in the cellulose fibril. Cellulose fibrils are the main reinforcement phase for plants, trees, and some bacteria, algae, and marine creature (tunicates). These cellulose fibrils, however, are composed of highly ordered regions (crystalline region) and disordered regions (amorphous region) as shown in Figure 10.6b.

\subsubsection{Structure of NFC}

Whereas cellulose can be isolated from a broad range of animals, plants, trees, and some bacteria, algae, and marine creature (tunicates), NFC must be extracted from cellulose through mechanical processes (e.g., grinding, high-pressurize homogenization, milling), chemical processes (e.g., TEMPO oxidation), or a combination of mechanical and chemical processes. Ilyas et al. (2018) isolated NFC from sugar palm cellulose through the process of high-pressure homogenization.

There is a huge range of cellulose particle types being investigated for commercial applications that range from flexible optoelectronics and biodegradable plastics to scaffolds for tissue regeneration. In addition, through the surface modification such as silane treatment, surfactant, carboxylation, TEMPO regioselective oxidation, acetylation, polymer grafting, polyelectrolyte adsorption, and sulfonation treatment, additional particle functionality can be gained. The surface modification is done to enhance the properties of nanocellulose for certain applications. SPNCCs have micrometer-long, ribbon-like, entangled fibrils that are composed of both amorphous and crystalline cellulose domains (Figure 10.7). 


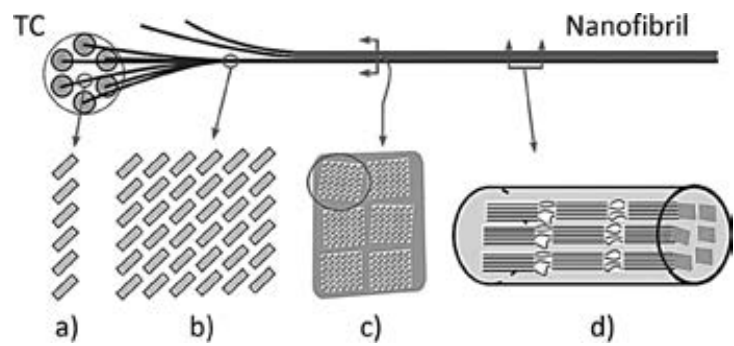

FIGURE 10.7 Wood nanofibril formation (a) single subunit of cellulose, (b) elementary fibril cross-section (c) nanofibril cross-section (d) nanofibril lateral section displaying the configuration of amorphous and crystalline regions. (Moon et al., 2011.)

NFC has high crystallinity with a high fraction of I $\beta$ crystal structure, whereas SPNCCs have nearly perfect crystallinity of approximately $85 \%$. In addition, the sugar palm NFC has highly viscous aqueous suspensions at low concentration. Extraction of nanofibrils from cellulose fibers involves selective mechanical processes that result in high crystallinity particles that are $2-10 \mathrm{~nm} \times$ micrometer in dimension. These dimensions, however, depend on the origin of the nanofibrils. For sugar palm fibers, the diameter dimension is 4-7 nm, whereas in wood the dimension is 3-5 nm (Siró and Plackett, 2010). Clowes and Juniper (1968) revealed that parenchyma cell wall widths were $20-25 \mathrm{~nm}$ in the form of intertwined aggregates. "Nanofiber" and "nanofibrillated cellulose (NFC)" are used as synonyms for "microfibril” (Siró and Plackett, 2010).

\subsection{EXTRACTION OF SUGAR PALM NFC}

The idea of NFC was first presented by Herrick et al. (1983) and Turbak et al. (1983), when they prepared nanosized cellulose from softwood pulps. Two stages occurred in the process of extracting cellulose fibers from cellulose sources materials. The initial stage is the pretreatment purification and homogenization of the source material, which is performed to obtain a more consistent reaction in subsequent treatments. The details of this stage depend on the type of cellulose material. For example, pretreatment for plants and woods involve the isolation of individual cellulose fibers through the partial or complete removal of matrix materials (e.g., lignin, hemicellulose, waxes), whereas for tunicate, algal, and bacterial cellulose, this phase includes the removal of the mantel and protein matrix, culturing methods and purifying steps for algal wall matrix removal, and culturing methods and washing steps for bacteria and other media removal, respectively. Comprehensive descriptions of these pretreatments are presented within the respective references for the following sources of material: algae (Imai et al., 2003), tunicates (Iwamoto et al., 2009), plants (Sanyang et al., 2016c), woods (Hubbe et al., 2008), and bacteria (Gatenholm and Klemm, 2010).

The second stage involves the disintegration of these purified cellulose materials into their microfibril or nanofibril components. Generally speaking, there are three 
processes that can be used to isolate cellulose fibers into nanocellulose: mechanical treatment, acid hydrolysis, and enzymatic hydrolysis. Mechanical treatment is used to produce NFC, whereas acid hydrolysis and enzymatic hydrolysis are used to produce NCC. However to obtain NCC, several of these treatments can be used separately, in sequence or in combination.

NFC can be obtained through the extraction of cellulose fibrils from microcrystalline cellulose, wood and plant fibers (e.g., sugar palm fiber), algae, tunicate, and bacterial sources of material using mechanical processes such as grinders/refiners, high-intensity ultrasonic treatment, high-pressure homogenizers, cryocrushing, and microfluidization. These processes create a very high shear force that causes cellulose macro/microfibrillar structures to transverse cleavage along the longitudinal axis, which results in the disintegration of long cellulose nanofibrils, termed nanofibrillated cellulose (Moon et al., 2011). NFC is isolated with different mechanical methods shown in Figure 10.8 and briefly described as follows:

1. High-pressure homogenization includes passing the cellulose slurry at high pressure into a vessel through a very small nozzle. High pressure, velocity, and shear and impact forces on the fluid produce shear rates in the stream and decrease the size of the fiber from micro to nanoscale (Frone, 2011).

2. Microfluidization uses an intensifier pump to increase the pressure and an interaction chamber to defibrillate the fibers using impact and shear force against channel walls and colliding streams (Ferrer et al., 2012). The mechanism of the fibrillation in microfluidization is similar to that of highpressure homogenization.

3. Grinding includes passing the pulp slurry between a rotating grind stone and a static grind stone. The grinder breaks down the cell wall as well as the hydrogen bonds of the fiber by shear force, which indirectly decreases the size of the fiber from individual pieces of pulp to nanoscale fibers (Qing et al., 2013).

4. Cryocrushing involves the immersion of the cellulosic fiber in water, followed by immersion in liquid nitrogen and subsequent crushing with a mortar and pestle. The mechanism of fibrillation in this process is to break down the cell wall of the frozen fiber by high impact force exerted on the ice crystals and thus detach nanofibers (Alemdar and Sain, 2008).

5. High-intensity ultrasonication isolates cellulose pulp with hydrodynamic forces of ultrasound using powerful oscillating power and high-intensity waves. This process leads to the formation, expansion, and implosion of microscopic gas bubbles as molecules absorb the ultrasonic energy (Zhou et al., 2012).

Cellulose fibers are usually processed through mechanical treatment in multiple passes to generate cellulose nanofibers that are smaller and more uniform in diameter. However, this treatment causes mechanical damage to the nanocrystalline region of the cellulose, which lowers the percentage of fiber crystallinity (Turbak et al., 1983). To remove partially fibrillated fractions and larger unfibrillated cellulose, a 

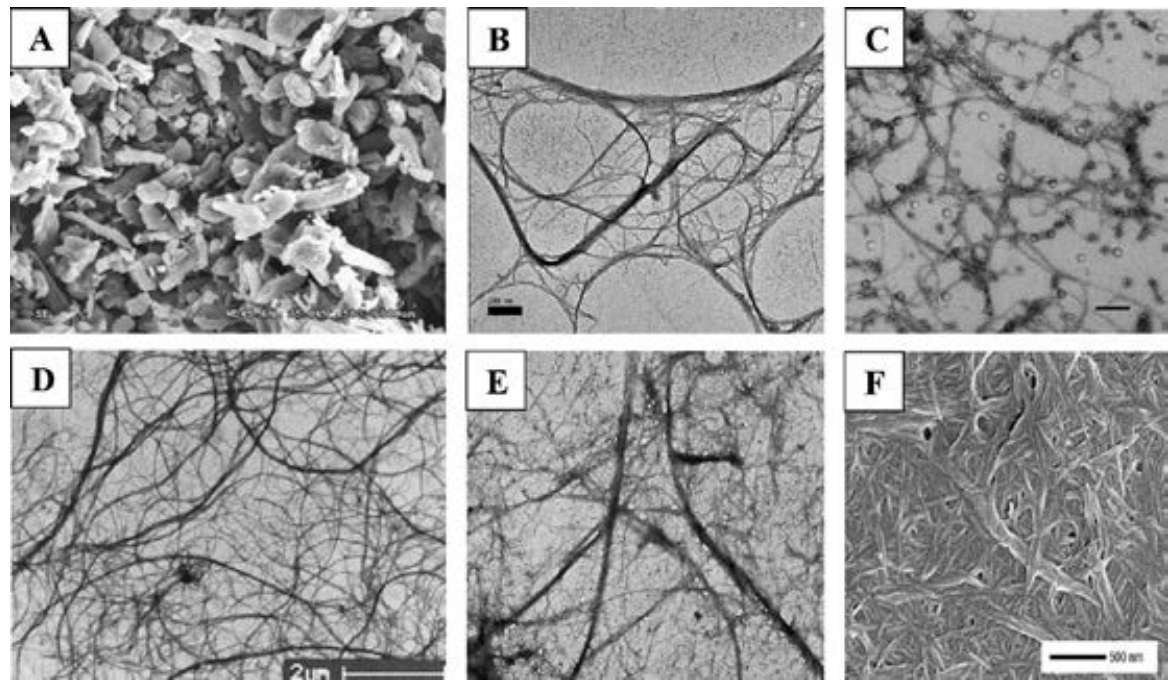

FIGURE 10.8 (A) SEM micrographs of microcrystalline cellulose (Menta et al., 2014). (B-F) TEM micrographs of (B) sugar palm NFC isolated with high-pressure homogenization through 5 passes at $500 \mathrm{MPa}$, (C) NFC isolated with microfluidization through 15 passes at $150 \mathrm{MPa}$ (Qing et al., 2013), (D) NFC after microgrinding for 6 hours at 1,500 rpm (Qing et al., 2013), (E) bleached frozen pulp after cryocrushing and treatment in a homogenizer (Alemdar and Sain, 2008), and (F) ultrasonication-derived nanocellulose (Zhou et al., 2012).

filtration step was introduced. NFC generated from these processes then undergo chemical treatment either to improve the NFC by chemically functionalizing the surface of nanoparticle or to remove the amorphous region to obtain highly crystalline nanoparticles (i.e., NCCs).

Therefore, to simplify the process of disintegrating cellulose microfibrils into smaller and thinner NFC (Figure 10.8), three recommendations have been implemented: all of the matrix material (lignin, hemicellulose, etc.) that reinforced the cellulose is partially removed (Sanyang et al., 2016c), use chemical treatment methods (Wu et al., 2007), and never use a dried source of material (Frenot, 2007).

The spaces between microfibril bundles collapse when the source material is dried and is therefore agglomerated, and it is more difficult to separate it because the hydrogen bonds are formed between the microfibril. Rehydration of dried materials does not displace all of the hydrogen bonds between fibrils, and the "weakening" effect is lost (Frenot et al., 2007). Similarly, in the purification stage, if the removal of matrix material was incomplete (e.g., only partial hemicelluloses were removed), these matrix materials can prevent the coalescence of the microfibril bundles during the drying period and ease the subsequent fibrillation of the material. In addition, transmitting a charge through the process of oxidation (2,2,6,6-tetramethyl-piperidinyl-1-oxyl radical (TEMPO) region-selective oxidation) or adsorption of charged polyelectrolytes (e.g., carboxymethyl cellulose treatment) on the surface of microfibril increases the interfabrillar repulsive forces 

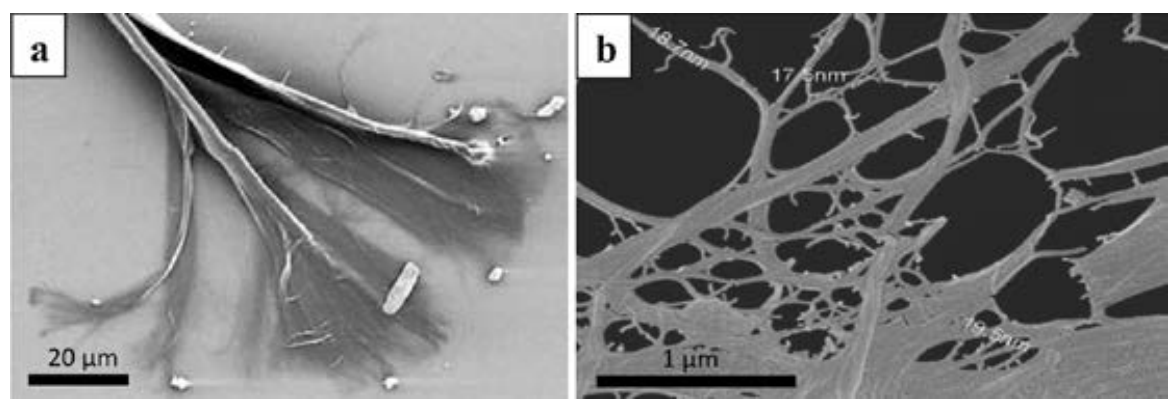

FIGURE 10.9 Disintegration of cellulose fibers into microfibrils and nanofibrils using TEMPO-mediated oxidation (Johnson et al., 2009) and high pressurize homogenizer (Ilyas et al., 2017a).

(Johnson et al., 2009). Figure 10.9 shows the disintegration of cellulose fibers into microfibrils using TEMPO-mediated oxidation.

\subsection{NANOCELLULOSE-REINFORCED STARCH-BASED COMPOSITES}

Nanocellulose is a bio-based material that is present plentifully in natural plants. These nanosized fibers have a huge potential for many applications, from scaffolding for tissue regeneration to flexible optoelectronics for telecommunications lasers, blue lasers, optical fibers, LED traffic lights, photo diodes, and solar cells. The properties of a nanocomposite depend on the physical and chemical properties of the polymer matrix and on interaction between the nanoparticles and the polymer matrix. Nanosized reinforced composites have many advantages compared to microsized reinforced composites, largely due to the large surface area with abundant surface hydroxyl groups (Majeed et al., 2013; Minelli et al., 2010; Sundari et al., 2012), high aspect ratio (Tee et al., 2013), high crystallinity, high thermal resistance (Hajaligol et al., 2001), good mechanical properties (Minelli et al., 2010; Kalia et al., 2011; Lavoine et al., 2012), and lower defects in reinforcing part (Khalil et al., 2014).

Due to these advantageous properties, awareness of using nanocellulose as reinforcement in loading-bearing in the development of innovative and low-cost biodegradable polymers has increased. Figure 10.10 shows SEM micrographs of the cross-section of TPS/NFC before and after degradation by white rot fungi. Generally speaking, bionanocomposites (TPS/NFC) are totally biodegradable and are found to fully disintegrate in ideal conditions. The biodegradation of nanocomposites is affected by different factors such as the type of organism, the polymer characteristics, and the nature of pretreatment. Bacteria and fungi are among the various microorganisms that are responsible for the degradation of both synthetic and natural plastics. TPS is fully biodegradable compared to conventional polymers, and the reinforcement of NFC with TPS has been proposed for diverse applications from cellular orientation to food packaging. It has been shown that nanocellulose 

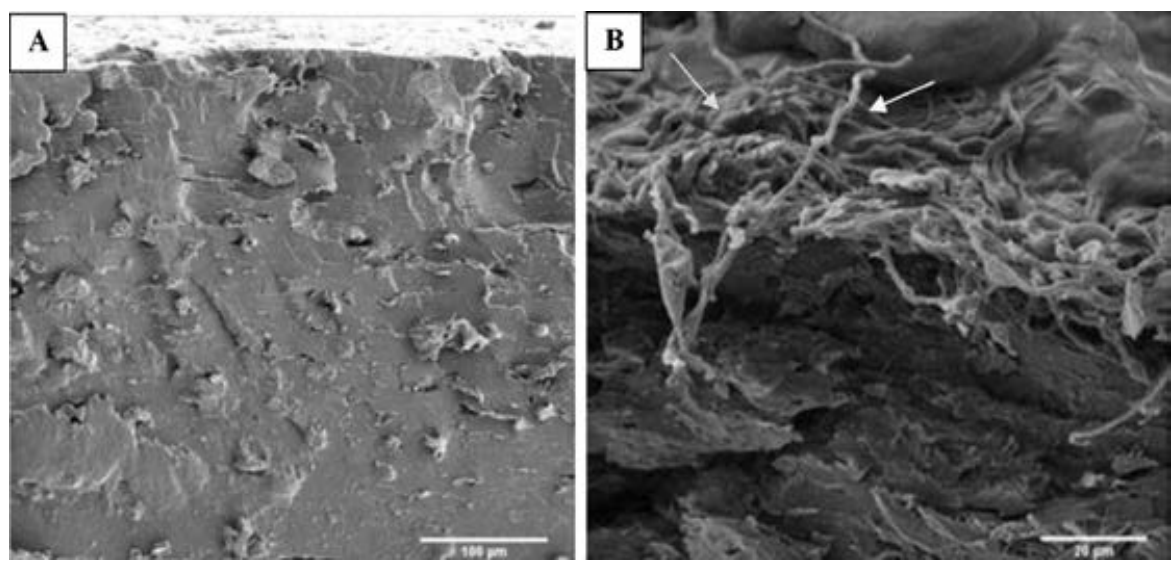

FIGURE 10.10 SEM micrographs of the cross-section of TPS/NFCs (A) before (B) after degradation by white rot fungi (see arrows). (Babaee et al., 2015.)

has a huge potential in flexible electronic device applications, in which ultrathin, aligned nanocellulose displayed a large piezoelectric response (Cruz-Tirado, 2017). Table 10.4 summarizes some of the recent scientific and industrial reports on NFC. The combination of NFC and polymers is another approach to produce conductive and flexible films in which the NFC component significantly improves the mechanical properties of conductive polymers.

Thus, the chiral nematic order can be preserved in the polymer reinforced with NFC. Moreover, NFC is extensively used as a filler in thermoplastic polymer matrices to produce highly durable nanocomposites with low production costs. The high strength, high crystallinity, and high aspect ratio (approximately 10-1,000 length/ diameter) of NFC are applicable for load bearing and stress transfer in thermoplastics (Abitbol et al., 2016). In addition, nanocomposite reinforcement has also been used in food-packaging applications of thermal stable starch, decreased water sensitivity, and for continuous papermaking (Abitbol et al., 2016). NFC also acts as a conventional reinforcement and plasticizer in amylopectin. Recently, many modifications of the nanocellulose surface have been performed to enhance compatibility with hydrophobic matrices. Tables 10.5 and 10.6 summarize the mechanical properties, sources, and preparations of NFC and NCCs, respectively; all of these were manufactured with the solution-casting method. It can be concluded that different types of starches and NFC reinforcement resulted in different mechanical properties.

\subsection{SPNCC-REINFORCED SPS BIOPOLYMERS}

SPS is one of the candidates for the replacement of non-biodegradable plastic due to its ease of availability and renewability, and it is affordable and-most importantly-biodegradable. In addition, these biopolymers have been explored widely for the manufacture of products such as food- and fruit-packaging films, plastic 


\section{TABLE 10.4}

\section{Summary of Recent Advances in NFC-Thermoplastic Composites}

\section{Polymer Component}

Starch

Maize amylopectin

Polyacrylamide

Polyvinyl alcohol

Carboxymethyl cellulose

Polyethylene

Polyethylene glycol

Amorphous dialcohol cellulose

Polyvinyl amine

Poly(butylene Injection molding

adipate-co-terephthalate)

Solution-casting

Solution-casting

Solution-casting

Solution-casting

Solution-casting

Extrusion surface

Layer by layer

\section{Manufacturing Technique Applications}

PEG-g-CNF ribbons via stretching hydrogel

Oxidation + reduction of $\mathrm{CNF}$

Self-healing polymer film (Kurihara and Isogai 2015)

Light-weight and high-performance materials for defense, infrastructure, and energy (Abitbol et al., 2016)

NFC: nanofibrillated cellulose; HDPE: high-density polyethylene; LDPE: low-density polyethylene; PEG-g-CNF: CNFs bearing covalently grafted PEG; CNF: cellulose nanofibrils.

From Abitbol et al., 2016

shopping bags, flushable liners, and medical delivery systems and devices (Ilyas et al., 2016). Starch polymers used as films, however, have been reported to have low water-barrier properties (Sanyang et al., 2016a). Thus, many studies have been conducted to improve the water sensitivity of starch-based materials without detracting from their biodegradability (Dias et al., 2011). The addition of nanosized natural fibers during the preparation of starch biopolymer films is an effective strategy to enhance the properties of packaging films.

Ilyas et al. (2017b) conducted experiments on the reinforcement of SPS biopolymer with SPNCC, which was extracted from the sugar palm fiber via the process 


\section{TABLE 10.5}

\section{Examples of Starch-Based Polymers, NFC Nanocomposites, and their Mechanical Properties}

\begin{tabular}{|c|c|c|c|c|c|}
\hline $\begin{array}{l}\text { Starch-Based } \\
\text { Polymers }\end{array}$ & NFC Sources & $\begin{array}{c}\text { NFC } \\
\text { Preparation }\end{array}$ & $\begin{array}{c}\text { Tensile } \\
\text { Strength (MPa) }\end{array}$ & $\begin{array}{c}\text { Young's } \\
\text { Modulus (MPa) }\end{array}$ & References \\
\hline Maize starch & Kenaf & $\begin{array}{l}\text { Super } \\
\text { masscolloider }\end{array}$ & 2.35 & 53.6 & $\begin{array}{l}\text { Karimi et al., } \\
2014\end{array}$ \\
\hline Corn starch & Kenaf & $\begin{array}{l}\text { Super } \\
\text { masscolloider }\end{array}$ & 38.0 & 141.0 & $\begin{array}{l}\text { Babaee et al., } \\
2015\end{array}$ \\
\hline Cassava starch & $\begin{array}{l}\text { Cassava } \\
\text { bagasse }\end{array}$ & $\begin{array}{l}\text { Hydrolyzed in } \\
6.5 \mathrm{M} \mathrm{H}_{2} \mathrm{SO}_{4} \\
40 \mathrm{~min}\end{array}$ & 4.8 & 84.3 & $\begin{array}{l}\text { Teixeira et al., } \\
2009\end{array}$ \\
\hline Mango puree & Wheat & - & 8.76 & 322.05 & $\begin{array}{l}\text { Azeredo et al., } \\
2009\end{array}$ \\
\hline Potato starch & $\begin{array}{l}\text { Softwood } \\
\text { wood flour }\end{array}$ & $\begin{array}{l}\text { Super } \\
\text { masscolloider }\end{array}$ & 17.5 & 1317.0 & $\begin{array}{l}\text { Hietala et al., } \\
2013\end{array}$ \\
\hline Maize starch & $\begin{array}{l}\text { Cotton } \\
\text { cellulose }\end{array}$ & $\begin{array}{l}\text { Hydrolyzed in } \\
6.5 \mathrm{M} \text { sulfuric } \\
\text { acid, } 75 \mathrm{~min}\end{array}$ & 0.35 & 3.12 & $\begin{array}{l}\text { Teixeira et al., } \\
\text { 2011b }\end{array}$ \\
\hline Maize starch & Wheat straw & $\begin{array}{l}\text { High } \\
\text { Pressurize } \\
\text { Homogenizer, } \\
15 \text { min }\end{array}$ & 6.75 & 220 & $\begin{array}{l}\text { Kaushik et al., } \\
2010\end{array}$ \\
\hline Potato starch & Rice straw & Ultrasonication & 5.01 & 160 & $\begin{array}{l}\text { Nasrabadi et al. } \\
2014\end{array}$ \\
\hline Corn starch & Bamboo fiber & - & 11.2 & 12.4 & $\begin{array}{l}\text { Llanos and } \\
\text { Tadini, } 2017\end{array}$ \\
\hline
\end{tabular}

of delignification, mercerization, and acid hydrolysis. The hydrolysis treatment was varied with times of 30, 45, and $60 \mathrm{~min}$. The results showed that water absorption decreased as $0.5 \%$ SPNCC was added to the starch biopolymer. Neat SPS gave the highest percentage of water absorption, followed by SPS/SPNCCs-30, SPS/ SPNCCs-45, and SPS/SPNCCs-60 (i.e., 111.3\%, 106.6\%, and 102.5\%, respectively). This is due to the tendency of higher concentrations of starch to absorb more water compared to films that have low concentrations of starch (Sahari et al., 2014). In addition, the adhesion between the SPNCCs and SPS tend to form strong hydrogen bonding via the physical interlocking with non-polar matrices and the $\mathrm{OH}-$ groups of hydrophilic polymer matrices (Minelli et al., 2010; Majeed et al., 2013).

In terms of biodegradation of the nanocomposite, the weight of neat SPS had lost 61.94\% after a 7-day soil burial test, whereas the SPS/SPNCCs bionanocomposite had lost 56.88\%, 55.74\%, and 52.61\% weight for SPS/SPNCCs-30, SPS/SPNCCs-45, and SPS/SPNCCs-60, respectively. The weight loss for the neat matrix was higher 
TABLE 10.6

Examples of Starch-Based Polymers, NCC Nanocomposites, and their Mechanical Properties

\begin{tabular}{|c|c|c|c|c|c|}
\hline $\begin{array}{l}\text { Starch-Based } \\
\text { Polymers }\end{array}$ & NCC Sources & $\begin{array}{c}\text { Isolation } \\
\text { Chemical, } \\
\text { Time of NCC }\end{array}$ & $\begin{array}{c}\text { Tensile } \\
\text { Strength (MPa) }\end{array}$ & $\begin{array}{l}\text { Young's } \\
\text { Modulus } \\
\text { (MPa) }\end{array}$ & References \\
\hline Pea starch & Hemp & $\begin{array}{l}64 \mathrm{wt} \% \mathrm{H}_{2} \mathrm{SO}_{4} \text {, } \\
4 \mathrm{~h}\end{array}$ & $3.9-11.5$ & $31.9-823.9$ & Cao et al., 2008b \\
\hline Pea starch & Flax & $\begin{array}{l}64 \mathrm{wt} \% \mathrm{H}_{2} \mathrm{SO}_{4} \text {, } \\
4 \mathrm{~h}\end{array}$ & $3.9-11.9$ & $31.9-498.2$ & Cao et al., 2008a \\
\hline Pea starch & Bamboo & $\begin{array}{l}50 \mathrm{wt} \% \mathrm{H}_{2} \mathrm{SO}_{4} \text {, } \\
48 \mathrm{~h}\end{array}$ & $2.5-12$ & $20.4-210.3$ & Liu et al., 2010 \\
\hline Maize starch & Tunicin & $\begin{array}{l}55 \mathrm{wt} \% \mathrm{H}_{2} \mathrm{SO}_{4}, \\
20 \mathrm{mins}\end{array}$ & $0.24-20$ & $51-315$ & $\begin{array}{l}\text { Anglès and } \\
\text { Dufresne, 2000, } \\
2001\end{array}$ \\
\hline Maize starch & $\begin{array}{l}\text { Waxy maize } \\
\text { starch }\end{array}$ & $\mathrm{H}_{2} \mathrm{SO}_{4}, 5$ days & $1-15$ & $11-320$ & $\begin{array}{l}\text { Angellier et al., } \\
\text { 2004, Angellier } \\
\text { et al., } 2006\end{array}$ \\
\hline Maize starch & Tunicate & - & 42 & $208-838$ & $\begin{array}{l}\text { Mathew et al., } \\
2008\end{array}$ \\
\hline Wheat starch & $\begin{array}{l}\text { Cottonseed } \\
\text { linter }\end{array}$ & $\begin{array}{l}64 \mathrm{wt} \% \\
\mathrm{H}_{2} \mathrm{SO}_{4}, 4 \mathrm{~h}\end{array}$ & $2.5-7.8$ & $36-301$ & Lu et al., 2005 \\
\hline Plasticized starch & $\begin{array}{l}\text { Cotton cellulose } \\
\text { powders }\end{array}$ & $\mathrm{H}_{2} \mathrm{SO}_{4}$ & - & - & Yang et al., 2014 \\
\hline Wheat starch & Ramie & $\begin{array}{l}64 \mathrm{wt} \% \\
\mathrm{H}_{2} \mathrm{SO}_{4}, 4 \mathrm{~h}\end{array}$ & $2.8-6.9$ & $56-480$ & Lu et al., 2006 \\
\hline Potato starch & $\mathrm{MCC}$ & $\begin{array}{l}64 \mathrm{wt} \% \mathrm{H}_{2} \mathrm{SO}_{4} \\
2 \mathrm{~h}\end{array}$ & 13.7 & 460 & Kvien et al., 2007 \\
\hline Wheat starch & $\mathrm{MCC}$ & $36.5 \mathrm{wt} \% \mathrm{HCl}$ & $3.15-10.98$ & - & Chang et al., 2010 \\
\hline Potato starch & Cotton linter & $\begin{array}{l}64 \mathrm{wt} \% \mathrm{H}_{2} \mathrm{SO}_{4} \text {, } \\
1 \mathrm{~h}\end{array}$ & 4.93 & - & $\begin{array}{l}\text { Noshirvani et al., } \\
2016\end{array}$ \\
\hline Potato starch & $\begin{array}{l}\text { Potato peel } \\
\text { waste }\end{array}$ & $\begin{array}{l}64 \mathrm{wt} \% \mathrm{H}_{2} \mathrm{SO}_{4} \\
90 \mathrm{mins}\end{array}$ & - & 460 & Chen et al., 2012 \\
\hline Maize starch & $\begin{array}{c}\text { Sugarcane } \\
\text { bagasse }\end{array}$ & $\begin{array}{l}64 \mathrm{wt} \% \mathrm{H}_{2} \mathrm{SO}_{4} \text {, } \\
3 \mathrm{~h}\end{array}$ & 17.4 & 520 & $\begin{array}{l}\text { Slavutsky and } \\
\text { Bertuzzi, } 2014\end{array}$ \\
\hline $\begin{array}{l}\text { Sugar palm } \\
\text { starch }\end{array}$ & $\begin{array}{l}\text { Sugar palm } \\
\text { fiber }\end{array}$ & $\begin{array}{l}60 \mathrm{wt} \% \mathrm{H}_{2} \mathrm{SO}_{4} \text {, } \\
45 \mathrm{~min}\end{array}$ & 11.5 & 180 & Ilyas et al., 2017b \\
\hline
\end{tabular}

compared to the bionanocomposite films. Two factors may contribute to these observations: the degree of crystallinity of SPNCCs in bionanocomposite films and water absorption by film. SPS absorbs more water than SPS/SPNCC films, exposing it to higher risk of attack by microbial organisms (Sahari et al., 2013). These microbial 

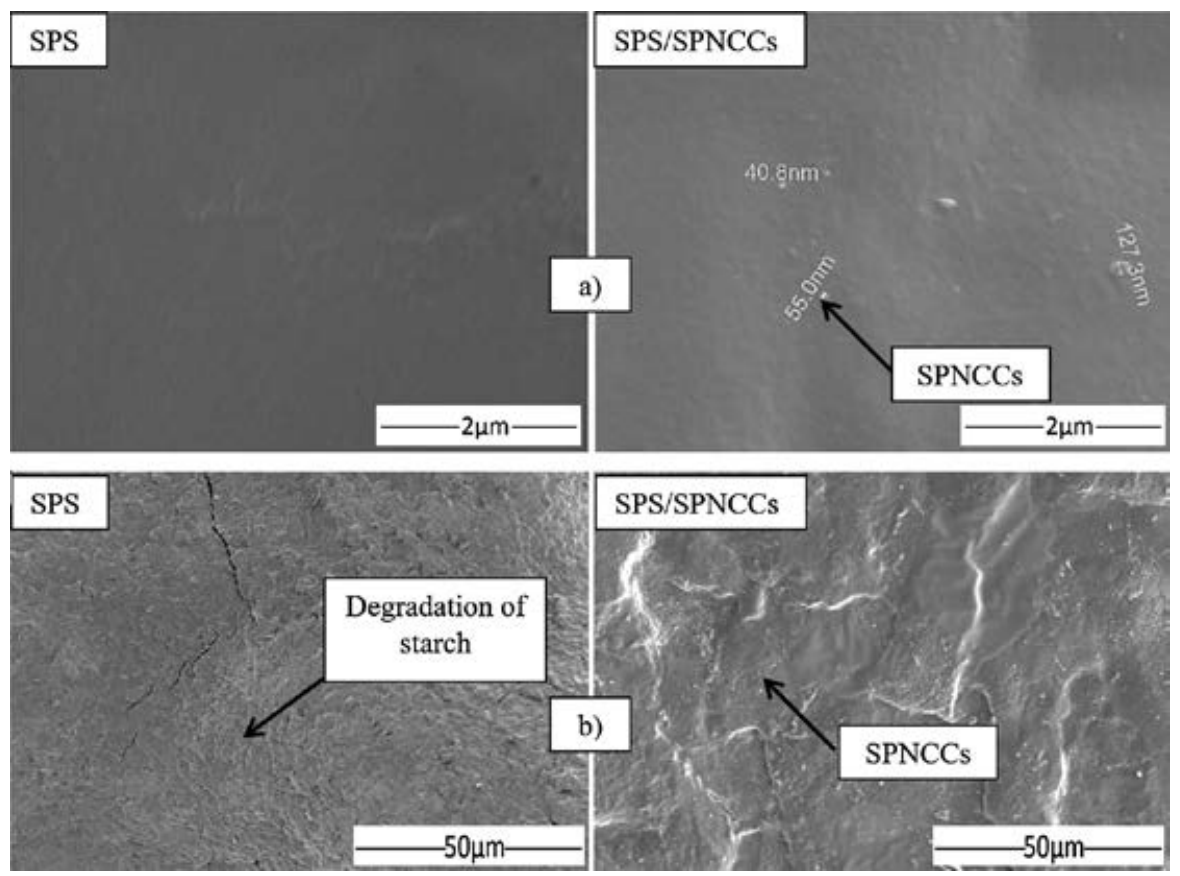

FIGURE 10.11 Surface morphology of SPS and SPS/SPNCCs bionanocomposite; a) before and b) after being buried. (Ilyas et al., 2018.)

organisms attack the SPS in the presence of water medium (Kiatkamjornwong et al., 1999). Alvarez et al. (2006) described that crystalline regions are more difficult to degrade. Compared to the control SPS film, SPS/SPNCC films contained higher crystallinity, which gave it a higher resistance to microbial organism attacks than starch. Figure 10.11 displays the surface morphology of SPS-based films with and without the addition of SPNCCs after being degraded in soil test for 168 hours. The micrograph of the neat SPS films showed a smooth and continuous surface with no trace of starch granules, cracks, or agglomerations of SPNCCs. High dispersion of SPNCCs (Figure 10.11b) is a good sign of strong interfacial adhesion between the two components of the SPS-SPNCC nanocomposite film.

Ilyas et al. (2017b) reported that the highest water-vapor permeability (WVP) is found in SPS films (i.e., $9.58 \times 10^{-10} \times \mathrm{g} \cdot \mathrm{s}^{-1} \cdot \mathrm{m}^{-1} \cdot \mathrm{Pa}^{-1}$ ) because of their hydrophilic nature and their sensitivity to moisture and the surrounding humidity, a factor that is hard to control (Wilhelm et al., 2003). The addition of SPNCCs into neat films reduced their WVP value by $11.17 \%$ due to the tortuous path caused by the rigid crystalline structure and the dispersion of SPNCCs in the starch polymer, which hinders the path of water molecules through the film matrix (Sanyang et al., 2016a; Slavutsky and Bertuzzi, 2014). The WVP of the film showed improvements of $11.17 \%, 14.72 \%$, and $19.94 \%$ for SPS/SPNCCs-30, SPS/SPNCCs-45, and SPS/SPNCCs-60, respectively, when the size of the SPNCCs reinforcing the bio-matrix is altered. This trend 
indicates that the smaller the size of the nanofibers, the harder it is for water to pass through the matrix SPS, thus improving the WVP of the neat SPS films.

\subsection{NANOCELLULOSE IN ANTIMICROBIAL FOOD-PACKAGING MATERIALS}

The term "active food-packaging system" refers to food-packaging products that not only passively protect the food from outsider danger, but also include some functionality to actively improve the stability and quality of food while it is in the packaging. One common active food-packaging system involves antimicrobial agents that are released onto the surface of food to preserve it from microbial attack (Azeredo, 2017).

Silver nanoparticles (AgNPs) have been extensively studied as antimicrobial food-packaging materials, with the results showing that nanocellulose reinforced with AgNPs had improved thermal stability. To change the material properties, several experiment were conducted to integrate additional properties into the structure of nanocellulose by functionalizing the nanocellulose with active groups. The common surface chemical modifications of nanocellulose can be categorized into three groups: substitution of hydroxyl groups with small molecules, such as TEMPO oxidation, silylated, alkenyl succinic anhydride-modified; polymer graft with different coupling agents, such as polyethylene glycol (PEG), polyethylene oxide, aliphatic polymer, polycaprolactone, and jeffamine macromolecules; and polymer grafts based on the "grafting form" approach with a radical polymerization involving ring-opening polymerization [i.e., atom transfer radical polymerization (ATRP) poly[6-(4-(4-methoxyphenylazo)phenoxyl)hexyl]methacrylate (PMMAZO), poly $(N, N$-dimethylaminoethyl methacrylate) (PDMAEMA), (ATRP)polystyrene, (ATRP)polyacrylic acid, polylactic acid, poly(N-isopropylacrylamide) and acetylated (PNiPAAm)] (Lin et al., 2012).

Dong et al. (2013) demonstrated that the accessible primary hydroxyls on the surface of nanofibrils are modified with anionic carboxylate group after the cellulose pulps are oxidized in a heterogeneous suspension with TEMPO as a catalyst. This is done to make the carboxylate group strongly interacted with AgNPs. The presence of AgNPs reduced NFC agglomeration in films due to the strong interaction between the carboxylate-Ag, which limited water solvation and hydrogen bonding between neighboring NFC. In addition, the chemical modified the antibacterial properties, which could be used for active-packaging applications.

However, another study by Xiu et al. (2012) indicated some concern about the potential toxicity of AgNPs. Due to the advantages of NFC properties such as a nonporous network and the virtuous formation of chemical interactions between NCF and loaded molecules, NFC has been proposed as a delivery and controlled-release agent (Lavoine et al., 2014a-d).

Lavoine et al. (2014b) used an NFC coating on paper to discharge caffeine as a model hydrophilic active compound. The researchers conducted three treatments in which paper was (a) soaked with caffeine (control sample); (b) soaked with caffeine and then coated with NFC; or (c) coated with an NFC/caffeine mixture. The results showed that the last treatment (i.e., coated with an NFC/caffeine mixture) was the 
best of these treatments due to the way in which the NFC network trapped caffeine, which promoted a more controlled and gradual release. As a result, the treated NFCreinforced polymer/paper matrix was said to have the best potential for applications in the food-packaging field.

In another study, Lavoine et al. (2014c) examined the capability of NFC coatings to control the release of the antibacterial chlorhexidine digluconate $(\mathrm{CHX})$. The experimental design was much the same as done in the previous study (Lavoine et al., 2014b), involving paper that was (a) soaked with CHX; (b) soaked with CHX and then coated with NFC; or (c) coated with an NFC/CHX mixture. Of these three treatments, the best treatment was the paper coated with an NFC/CHX mixture because the paper still remained in good condition after within 45 days, compared to the paper in treatments (a) and (b), which remained in good condition for 18 and 30 days, respectively.

Lavoine et al. (2014d) also developed controlled-release systems based on paper coated with NFC and $\beta$-cyclodextrin (BCD) to distribute the antibacterial CHX. The BCD was intended to control the CHX release over time, and the NFC was expected to control the burst effect. When the BCD was used alone without NFC, it promoted a slow release of $\mathrm{CHX}$, whereas the combination of NFC/BCD was more suitable for rapid release. Lavoine et al. (2014e) continued to investigate the combined action of $\mathrm{NFC/BCD}$ using carvacrol as the controlled-release agent instead of CHX. In the initial process, the BCD solution, NFC suspension, or both were used to mix with carvacrol, and then these final mixed solutions were applied as coatings onto paper. The results indicated that the BCD-grafted paper and the NFC/BCD-grafted paper retained antibacterial activity against Bacillus subtilis for 14 and 16 hours, respectively, whereas the non-grafted paper (control) retained antibacterial activity for only 4 hours.

\section{CONCLUSIONS}

Even though the issue of nanocellulose has been explored extensively over the past two decades, there is still room for new developments, predominantly in the field of food-packaging material. Pushing the boundaries of SPNCC into high-performance functional plastics to create organic materials with smart, greener footprints and tunable properties is promising for the future, especially as low-cost commercial sources of cellulose continue to emerge. The development of such green nanocomposites can generate significant environmental improvements, addressing the disposal of plastic waste and the reduction of the carbon footprint of commodities derived from petroleum-based polymers.

\section{ACKNOWLEDGMENTS}

The authors thank Universiti Putra Malaysia for financial support through the Graduate Research Fellowship (GRF) scholarship, Universiti Putra Malaysia Grant scheme Hi-COE (6369107) and FRGS//TK05/UPM/01/1 (5540048). The authors are grateful to Dr. Muhammed Lamin Sanyang of Gambia for guidance throughout the experiment. The authors also thank the Forest Research Institute Malaysia (FRIM) and Dr. Rushdan Ibrahim for their advice and fruitful discussions. 


\section{REFERENCES}

Abitbol, T., Rivkin, A., Cao, Y., Nevo, Y., Abraham, E., Ben-Shalom, T., Lapidot, S., and Shoseyov, O. (2016). Nanocellulose, a tiny fiber with huge applications. Current Opinion in Biotechnology, 39, 76-88.

Alemdar, A., and Sain, M. (2008). Isolation and characterization of nanofibers from agricultural residues - wheat straw and soy hulls. Bioresource Technology, 99(6), 1664-1671.

Alvarez, V.A., Ruseckaite, R. A., and Vázquez, A. (2006). Degradation of sisal fiber/ mater Bi-Y biocomposites buried in soil. Polymer Degradation and Stability, 91(12), $3156-3162$.

Angellier, H., Choisnard, Molina-Boisseau L., Patrick S., and Dufresne, A. (2004). Optimization of the preparation of aqueous suspensions of waxy maize starch nanocrystals using a response surface methodology. Biomacromolecules, 5(4), $1545-1551$.

Angellier, H., Molina-Boisseau, S., Dole, P., and Dufresne, A. (2006). Thermoplastic starchwaxy maize starch nanocrystals nanocomposites. Biomacromolecules, 7(2), 531-539.

Anglès, M., Neus, and Dufresne, A. (2000). Plasticized starch/tunicin whiskers nanocomposites. 1. Structural analysis. Macromolecules, 33(22), 8344-8353.

Anglès, M., Neus, and Dufresne, A. (2001). Plasticized starch/tunicin whiskers nanocomposite materials. 2. Mechanical behavior. Macromolecules, 34(9), 2921-2931.

Avérous, L. (2004). Biodegradable multiphase systems based on plasticized starch: A review. Journal of Macromolecular Science, Part C: Polymer Reviews, 44(3), 231-274.

Azeredo, H., M.C., Mattoso, L.H.C., Wood, D., Williams, T.G., Avena-Bustillos, R.B., and McHugh, T.H. (2009). Nanocomposite edible films from mango puree reinforced with cellulose nanofibers. Journal of Food Science, 74(5), N31-N35.

Azeredo, H.M.C., Rosa, M.F., and Mattoso, L.H.C. (2017). Nanocellulose in bio-based food packaging applications. Industrial Crops and Products, 97, 664-671.

Azizi, S., Said, M.Y., Alloin, F., and Dufresne, A. (2005). Review of recent research into cellulosic whiskers, their properties and their application in nanocomposite field. Biomacromolecules, 6(2), 612-626.

Babaee, M., Jonoobi, M., Hamzeh, Y., and Ashori, A. (2015). Biodegradability and mechanical properties of reinforced starch nanocomposites using cellulose nanofibers. Carbohydrate Polymers, 132(3), 1-8.

Bhattacharya, D., Louis, T. G., and Winter, W.T. (2008). Isolation, preparation and characterization of cellulose microfibers obtained from bagasse. Carbohydrate Polymers, 73(3), 371-377.

Cao, X., Chen, Y., Peter, R.C., and Huneaul, M.A. (2007). Preparation and properties of plasticized starch/multiwalled carbon nanotubes composites. Journal of Applied Polymer Science, 106(2), 1431-1437.

Cao, X., Chen, Y., Chang, P., Muir, A. D., and Falk, G. (2008a). Starch-based nanocomposites reinforced with flax cellulose nanocrystals. Express Polymer Letters, 2(7), 502-510.

Cao, X., Chen, Y., Peter, R.C., Stumborg, M., and Huneault, M.A. (2008b). Green composites reinforced with hemp nanocrystals in plasticized starch. Journal of Applied Polymer Science, 109(6), 3804-3810.

Cao, X., Habibi, Y., Magalhães, W., Rojas, O.J., and Lucia, L.A. (2011). Cellulose nanocrystals-based nanocomposites: fruits of a novel biomass research and teaching platform. Current Science, 100(8), 1172-176.

Chang, P.R., Ruijuan, J., Zheng, P., Yu, J., and Ma, X. (2010). Preparation and properties of glycerol plasticized-starch (gps)/cellulose nanoparticle (cn) composites. Carbohydrate Polymers, 79(2), 301-305.

Chen, B., and Evans, J.R.G. (2005). Thermoplastic starch-clay nanocomposites and their characteristics. Carbohydrate Polymers, 61(4), 455-463. 
Chen, D., Lawton, D., Thompson, M.R., and Liu, Q. (2012). Biocomposites reinforced with cellulose nanocrystals derived from potato peel waste. Carbohydrate Polymers, 90(1), 709-716.

Cherian, M.B., Laly, A.P., Tham, G.M., Kottaisamy, T.S. (2008). A novel method for the synthesis of cellulose nanofibril whiskers from banana fibers and characterization. Journal of Agricultural and Food Chemistry, 56(14), 5617-5627.

Clowes, F.A.L., and Juniper, B.E. (1968). Plant Cells. Oxford, UK: Blackwell Scientific Publications.

Coffin, D.R., and Fishman, M.L. (1994). Physical and mechanical properties of highly plasticized pectin/starch films. Journal of Applied Polymer Science, 54(9), 1311-1320.

Cruz-Tirado, J.P., Tapia-Blácido, D.R., and Siche, R. (2017). Influence of proportion and size of sugarcane bagasse fiber on the properties of sweet potato starch foams. IOP Conference Series: Materials Science and Engineering, 225, 12180.

Dias, A.B., Carmen M.O., Müller, F.D.S.L. and Laurindo, J.B. (2011). Mechanical and barrier properties of composite films based on rice flour and cellulose fibers. Food Science and Technology, 44(2), 535-542.

Dong, H., Snyder, J.F., Tran, D.T. and Leadore, J.L. (2013). Hydrogel, aerogel and film of cellulose nanofibrils functionalized with silver nanoparticles. Carbohydrate Polymers, 95(2), 760-767.

Eichhorn, S.J. (2011). Cellulose nanowhiskers: Promising materials for advanced applications. Soft Matter, 7(2), 303-315.

Fahma, F., Hori, N., Iwamoto, S., Iwata, T. and Takemura, A. (2016). Cellulose nanowhiskers from sugar palm fibers. Emirates Journal of Food and Agriculture, 28(8), 566-571.

Farahbakhsh, N., Richard A., Venditti and Jur, J.S. 2014. Mechanical and thermal investigation of thermoplastic nanocomposite films fabricated using micro- and nano-sized fillers from recycled cotton T-shirts. Cellulose, 21(4), 2743-2755.

Ferrer, A., Filpponen, I., Rodríguez, A., Laine, J., and Rojas, O.J. (2012). Valorization of residual empty palm fruit bunch fibers (EPFBF) by microfluidization: Production of nanofibrillated cellulose and EPFBF nanopaper. Bioresource Technology, 125, 249-255.

Fishman, M.L., Coffin, D.R., Konstance, R.P., and Onwulata, C.I. (2000). Extrusion of pectin/starch blends plasticized with glycerol. Carbohydrate Polymers, 41(4), 317-325.

Flauzino N., Wilson, P., Silvério, H.A., Dantas, N.O. and Pasquini, D. (2013). Extraction and characterization of cellulose nanocrystals from agro-industrial residue: Soy hulls. Industrial Crops and Products, 42, 480-488.

French, A., and Murphy, V. (1976). Review of starch polymorphs. Cereal Foods World, 21(8), 429-429.

Frenot, A., Henriksson, M.W., and Walkenström, P. (2007). Electrospinning of CelluloseBased Nanofibers. Journal of Applied Polymer Science, 103(3), 1473-1482.

Frone, A.N., Panaitescu, D.M., and Donescu, D. (2011). Some aspects concerning the isolation of cellulose micro- and nano-fibers. UPB Scientific Bulletin, Series B: Chemistry and Materials Science, 73(2), 133-152.

Gatenholm, P., and Klemm, D. (2010). Bacterial nanocellulose as a renewable material for biomedical applications. MRS Bulletin, 35(3), 208-213.

Hajaligol, M.R., Waymack, B., and Kellogg, D. (2001). Low temperature formation of aromatic hydrocarbon from pyrolysis of cellulosic materials. Fuel, 80, 1799-1807.

Halley, P.J. (2005). Thermoplastic starch biodegradable polymers. In: Biodegradable Polymers for Industrial Applications (ed. Robin Smith). New York: Elsevier, 140-159.

Herrick, F.W., Casebier, R.L., Hamilton, J.K., and Sandberg, K.R. (1983). Microfibrillated cellulose: Morphology and accessibility. Journal of Applied Polymer Science: Applied Polymer Symposium, 37(9), 797-813.

Hietala, M., Mathew, A.P., and Oksman, K. (2013). Bionanocomposites of thermoplastic starch and cellulose nanofibers manufactured using twin-screw extrusion. European Polymer Journal, 49(4), 950-956. 
Hubbe, M.A., Orlando, J., Rojas, L.A., and Sain, M. (2008). Cellulosic nanocomposites: A review. BioResources, 3(3), 929-980.

Ilyas, R.A., Sapuan, S.M., Sanyang, M.L., and Ishak, M.R. (2016). Nanocrystalline cellulose reinforced starch-based nanocomposite: A review. In 5th Postgraduate Seminar on Natural Fiber Composites. Serdang, Selangor: Universiti Putra Malaysia, 82-87.

Ilyas, R.A., Sapuan, S.M., Ishak, M.R., and Zainudin, E.S. (2017a). Effect of delignification on the physical, thermal, chemical, and structural properties of sugar palm fiber. BioResources, 12(4), 8734-8754.

Ilyas, R.A., Salit, M.S., Sanyang, M.L., and Ishak M.R. (2017b). Nanocrystalline cellulose as reinforcement for polymeric matrix nanocomposites and its potential applications: A review. Current Analytical Chemistry, 13. doi: 10.2174/1573411013666171003155624.

Ilyas, R.A., Sapuan, S.M. and Ishak, M.R. (2018). Isolation and characterization of nanocrystalline cellulose from sugar palm fibers (Arenga pinnata). Carbohydrate Polymers, 181, 1038-1051.

Imai, T., Putaux, J., and Sugiyama, J. (2003). Geometric phase analysis of lattice images from algal cellulose microfibrils. Polymer, 44(6), 1871-1879.

Islam, T.M., Alam, M.M., and Zoccola, M. (2013). Review on modification of nanocellulose for application in composites. International Journal of Innovative Research in Science, Engineering and Technology, 2(10), 5444-5451.

Iwamoto, S., Kai, W., Isogai, A., and Iwata, T. (2009). Elastic modulus of single cellulose microfibrils from tunicate measured by atomic force microscopy. Biomacromolecules, 10(9), 2571-2576.

Johnson, R.K., Zink-Sharp, A., Renneckar, S.H., and Glasser, W.G. (2009). A new bio-based nanocomposite: Fibrillated tempo-oxidized celluloses in hydroxypropylcellulose matrix. Cellulose, 16(2), 227-238.

Jonoobi, M., Oladi, R., Davoudpour, Y., Oksman, K., Dufresne, A., Hamzeh, Y., and Davoodi, R. (2015). Different preparation methods and properties of nanostructured cellulose from various natural resources and residues: A review. Cellulose, 22(2), 935-969.

Jumaidin, R., Sapuan, S.M., Jawaid, M., Ishak, M.R., and Sahari, J. (2017a). Effect of seaweed on mechanical, thermal, and biodegradation properties of thermoplastic sugar palm starch/agar composites. International Journal of Biological Macromolecules, 99, 265-273.

Jumaidin, R., Sapuan, S.M., Jawaid, M., Ishak, M.R., and Sahari, J. (2017b). Thermal, mechanical, and physical properties of seaweed/sugar palm fiber reinforced thermoplastic sugar palm starch/agar hybrid composites. International Journal of Biological Macromolecules, 97, 606-615.

Kalia, S., Dufresne, A., Cherian, B.M., Kaith, B.S., Avérous, L., Njuguna, J., and Nassiopoulos, E. (2011). Cellulose-based bio- and nanocomposites: A review. International Journal of Polymer Science, 2011, 1-35.

Karimi, S., Tahir, P., Dufresne, A., Karimi, A., and Abdulkhani, A. (2014). A comparative study on characteristics of nanocellulose reinforced thermoplastic starch biofilms prepared with different techniques. Nordic Pulp and Paper Research Journal, 29(1), $41-45$.

Kaushik, A., Singh, M., and Verma, G. (2010). Green nanocomposites based on thermoplastic starch and steam exploded cellulose nanofibrils from wheat straw. Carbohydrate Polymers, 82(2), 337-345.

Kelfkens, M., and Hamer, R.J. (1991). Agronomic factors related to the quality of wheat for the starch industry. Part II: Nitrogen fertilisation and overall conclusions. Starch/ Stärke, 43(9), 344-347.

Khalil, H.P.S.A., Davoudpour, Y., Islam, M.Z., Mustapha, A., Sudesh, K., Dungani, R., and Jawaid, M. (2014). Production and modification of nanofibrillated cellulose using various mechanical processes: A review. Carbohydrate Polymers, 99, 649-665. 
Kiatkamjornwong, S., Sonsuk, M., Wittayapichet, S., Prasassarakich, P., and Vejjanukroh, P. (1999). Degradation of styrene-g-cassava starch filled polystyrene plastics. Polymer Degradation and Stability, 66(3), 323-335.

Klemm, D., Kramer, F., Moritz, S., Lindström, T., Ankerfors, M., Gray, D., and Dorris, A. (2011). Nanocelluloses: A new family of nature-based materials. Angewandte Chemie - International Edition, 50(24), 5438-5466.

Kurihara, T., and Isogai, A. (2015). Mechanism of TEMPO-oxidized cellulose nanofibril film reinforcement with poly(acrylamide). Cellulose, 22(4), 2607-2617.

Kvien, Ingvild, Sugiyama, J., Votrubec, M., and Oksman, K. (2007). Characterization of starch based nanocomposites. Journal of Materials Science, 42(19), 8163-8171.

Larsson, P.A., Berglund, L.A., and Wågberg, L. (2014). Ductile all-cellulose nanocomposite films fabricated from core-shell structured cellulose nanofibrils. Biomacromolecules, 15(6), 2218-2223.

Lavoine, N., Desloges, I., Dufresne, A., and Bras, J. (2012). Microfibrillated cellulose: Its barrier properties and applications in cellulosic materials: A review. Carbohydrate Polymers, 90(2), 735-764.

Lavoine, N., Desloges, I., and Bras, J. (2014a). Microfibrillated cellulose coatings as new release systems for active packaging. Carbohydrate Polymers, 103(1), 528-537.

Lavoine, N., Desloges, I., Khelifi, B., and Bras, J. (2014b). Impact of different coating processes of microfibrillated cellulose on the mechanical and barrier properties of paper. Journal of Materials Science, 49(7), 2879-2893.

Lavoine, N., Desloges, I., Sillard, C., and Bras, J. (2014c). Controlled release and long-term antibacterial activity of chlorhexidine digluconate through the nanoporous network of microfibrillated cellulose. Cellulose, 21(6), 4429-4442.

Lavoine, N., Givord, C., Tabary, N., Desloges, I., Martel, B., and Bras, J. (2014d). Elaboration of a new antibacterial bio-nano-material for food-packaging by synergistic action of cyclodextrin and microfibrillated cellulose. Innovative Food Science and Emerging Technologies, 26, 330-340.

Lavoine, N., Tabary, N., Desloges, I., Martel, B., and Bras, J. (2014e). Controlled release of chlorhexidine digluconate using $\beta$-cyclodextrin and microfibrillated cellulose. Colloids and Surfaces B: Biointerfaces, 121, 196-205.

Lepifre, S., Froment, M., Cazaux, F., Houot, S., Lourdin, D., Coqueret, X., Lapierre, C., and Baumberger, S. (2004). Lignin incorporation combined with electron-beam irradiation improves the surface water resistance of starch films. Biomacromolecules, 5(5), 1678-1686.

Li, J., Song, Z., Li, D., Shang, S., and Guo, Y. (2014). Cotton cellulose nanofiber-reinforced high density polyethylene composites prepared with two different pretreatment methods. Industrial Crops and Products, 59, 318-328.

Lin, N., Huang, J., and Dufresne, A. (2012). Preparation, properties and applications of polysaccharide nanocrystals in advanced functional nanomaterials: A review. Nanoscale, 4(11), 3274.

Liu, D., Zhong, T., Chang, P.R., Li, K., and Wu, Q. (2010). Starch composites reinforced by bamboo cellulosic crystals. Bioresource Technology, 101(7), 2529-2536.

Llanos, J.H.R., and Tadini, C.C. (2017). Preparation and characterization of bio-nanocomposite films based on cassava starch or chitosan, reinforced with montmorillonite or bamboo nanofibers. International Journal of Biological Macromolecules, 107(Part A), 371-382.

Lu, Y., Weng, L., and Cao, X. (2005). Biocomposites of plasticized starch reinforced with cellulose crystallites from cottonseed linter. Macromolecular Bioscience, 5(11), 1101-1107.

Lu, Y., Weng, L., and Cao, X. (2006). Morphological, thermal and mechanical properties of ramie crystallites reinforced plasticized starch biocomposites. Carbohydrate Polymers, 63(2), 198-204. 
Majeed, K., Jawaid, M., Hassan, A., Abu Bakar, A., Abdul Khalil, H.P.S., Salema, A.A., and Inuwa, I. (2013). Potential materials for food packaging from nanoclay/natural fibers filled hybrid composites. Materials and Design, 46, 391-410.

Mathew, A.P., Thielemans, W., and Dufresne, A. (2008). Mechanical properties of nanocomposites from sorbitol plasticized starch and tunicin whiskers. Journal of Applied Polymer Science, 109(6), 4065-4074.

Menta, V.G.K., Vuppalapati, R.R., Chandrashekhara, K., and Schuman, T. (2014). Manufacturing of transparent composites using vacuum infusion process. Polymers and Polymer Composites, 22(9), 843-850.

Minelli, M., Baschetti, M.G., Doghieri, F., Ankerfors, M., Lindström, T., Siró, I., and Plackett, D. (2010). Investigation of mass transport properties of microfibrillated cellulose ( $\mathrm{mfc}$ ) films. Journal of Membrane Science, 358(1-2), 67-75.

Moon, R.J., Martini, A., Nairn J., Simonsen, J., and Youngblood, J. (2011). Cellulose nanomaterials review: Structure, properties and nanocomposites. Chemical Society Reviews, 40(7), 3941.

Morán, J.I., Alvarez, V.A., Cyras, V.P., and Vázquez, A. (2008). Extraction of cellulose and preparation of nanocellulose from sisal fibers. Cellulose, 15(1), 149-159.

Nasrabadi, B., Behzad, T., and Bagheri, R. (2014). Preparation and characterization of cellulose nanofiber reinforced thermoplastic starch composites. Fibers and Polymers, 15(2), 347-354.

Ng, H., Sin, L.T., Tee, T.T., Bee, S., Hui, D., Low, C., and Rahmat, A.R. (2015). Extraction of cellulose nanocrystals from plant sources for application as reinforcing agent in polymers. Composites Part B: Engineering, 75, 176-200.

Noshirvani, N., Ghanbarzadeh, B., Fasihi, H., and Almasi, H. (2016). Starch-PVA nanocomposite film incorporated with cellulose nanocrystals and MMT: A comparative study. International Journal of Food Engineering, 12(1), 37-48.

Oun, A.A., and Rhim, J. (2015). Preparation and characterization of sodium carboxymethyl cellulose/cotton linter cellulose nanofibril composite films. Carbohydrate Polymers, 127, 101-9.

Prakobna, K., Galland, S., and Berglund, L.A. (2015). High-performance and moisturestable cellulose-starch nanocomposites based on bioinspired core-shell nanofibers. Biomacromolecules, 16(3), 904-912.

Qing, Y., Sabo, R., Zhu, J.Y., Agarwal, U., Cai, Z., and Wu, Y. (2013). A comparative study of cellulose nanofibrils disintegrated via multiple processing approaches. Carbohydrate Polymers, 97(1), 226-234.

Reddy, M.M., Vivekanandhan, S., Misra, M., Sujata, K., Bhatia, and Mohanty, A.K. (2013). Biobased plastics and bionanocomposites: Current status and future opportunities. Progress in Polymer Science, 38(10-11), 1653-1689.

Rhim, J. (2007). Potential use of biopolymer-based nanocomposite films in food packaging applications. Food Science and Biotechnology, 16(5), 691-709.

Rosa, M.F., Medeiros, E.S., Malmonge, J.A., Gregorski, K.S., Wood, D.F., Mattoso, L.H.C., Glenn, G., Orts, W.J., and Imam, S.H. (2010). Cellulose nanowhiskers from coconut husk fibers: Effect of preparation conditions on their thermal and morphological behavior. Carbohydrate Polymers, 81(1), 83-92.

Sahari, J, Sapuan, S.M., Zainudin, E.S., and Maleque, M.A. (2012). Effect of water absorption on mechanical properties of sugar palm fiber reinforced sugar palm starch (SPF/SPS) biocomposites. Journal of Biobased Materials and Bioenergy, 6, 1-5.

Sahari, J., Sapuan, S.M., Zainudin, E.S., and Maleque, M.A. (2013). Thermo-mechanical behaviors of thermoplastic starch derived from sugar palm tree (Arenga pinnata). Carbohydrate Polymers, 92(2), 1711-1716.

Sahari, J., Salit M. S., Zainudin, E.S., and Maleque, M.A. (2014). Degradation characteristics of SPF/SPS biocomposites fabrication of SPF/SPS biocomposites. Fibers and Textiles in Eastern Europe, 22(5107), 96-98. 
Sanyang, M.L., Sapuan, S.M., Jawaid, M., Ishak, M.R., and Sahari, J. (2015a). Effect of glycerol and sorbitol plasticizers on physical and thermal properties of sugar palm starch based films. In: Recent Advances in Environment, Ecosystems and Development Effect. Kuala Lumpur, Malaysia: WSEAS, 157-162.

Sanyang, M.L., Sapuan, S.M., Jawaid, M., Ishak, M.R., and Sahari, J. (2015b). Plasticizing and anti-plasticizing effect of different plasticizers on tensile properties of sugar palm starch films. In: Postgraduate Symposium on Biocomposite Technology 2015. Serdang, Selangor, Malaysia.

Sanyang, M.L., Sapuan, S.M., Jawaid, M., Ishak, M.R., and Sahari, J. (2016a). Development and characterization of sugar palm starch and poly(lactic acid) bilayer films. Carbohydrate Polymers, 146, 36-45.

Sanyang, M.L., Sapuan, S.M., Jawaid, M., Ishak, M.R., and Sahari, J. (2016b). Recent developments in sugar palm (Arenga Pinnata) based biocomposites and their potential industrial applications: A review. Renewable and Sustainable Energy Reviews, 54, 533-549.

Sanyang, M.L., Sapuan, S.M., Jawaid, M., Ishak, M.R., and Sahari, J. (2016c). Effect of sugar palm-derived cellulose reinforcement on the mechanical and water barrier properties of sugar palm starch biocomposite films. BioResources, 11(2), 4134-4145.

Savadekar, N.R., and Mhaske, S.T. (2012). Synthesis of nanocellulose fibers and effect on thermoplastics starch based films. Carbohydrate Polymers, 89(1), 146-151.

Silvério, A.H., Flauzino, N., Dantas, N.O., and Pasquini, D. (2013). Extraction and characterization of cellulose nanocrystals from corncob for application as reinforcing agent in nanocomposites. Industrial Crops and Products, 44, 427-436.

Siró, I., and Plackett, D. (2010). Microfibrillated cellulose and new nanocomposite materials: A review. Cellulose, 17(3), 459-494.

Slavutsky, A.M., and Bertuzzi, M.A. (2014). Water barrier properties of starch films reinforced with cellulose nanocrystals obtained from sugarcane bagasse. Carbohydrate Polymers, 110, 53-61.

Sonia, A., Dasan, K. P., and Alex, R. (2013). Celluloses microfibers (CMF) reinforced poly(ethylene-co-vinyl acetate) (EVA) composites: Dynamic mechanical, gamma and thermal ageing studies. Chemical Engineering Journal, 228, 1214-1222.

Sumaiyah, W., B., Karsono, Nasution, M.P., and Gea, S. (2014). Preparation and characterization of nanocrystalline cellulose from sugar palm bunch. International Journal of PharmTech, 6(2), 814-820.

Sundari, T.M., and Ramesh, A. (2012). Isolation and characterization of cellulose nanofibers from the aquatic weed water hyacinth Eichhornia crassipes. Carbohydrate Polymers, 87(2), 1701-1705.

Tang, H., Butchosa, N., and Zhou, Q. (2015). A transparent, hazy, and strong macroscopic ribbon of oriented cellulose nanofibrils bearing poly(ethylene glycol). Advanced Materials, 27(12), 2070-2076.

Tawakkal, S., M.I., Rosnita, Talib, Abdan, K., and Ling, C. (2012). Mechanical and physical properties of kenaf-derived cellulose (KDC)-filled polylactic acid (PLA) composites. BioResources, 7(2), 1643-1655.

Tee, T., Sin, S.T., Gobinath, R., Bee, S., Hui, D., Rahmat, A.R., Kong, I., and Fang, Q. (2013). Investigation of nano-size montmorillonite on enhancing polyvinyl alcohol-starch blends prepared via solution cast approach. Composites Part B: Engineering, 47(April), 238-247.

Teixeira, E.M., Pasquini, D., Curvelo, A.A.S., Corradini, E., Belgacem, M.N., and Dufresne, A. (2009). Cassava bagasse cellulose nanofibrils reinforced thermoplastic cassava starch. Carbohydrate Polymers, 78(3), 422-431.

Teixeira, E.M., Bondancia, T.J., Teodoro, K.B.R., Corrêa, A.C., Marconcini, J.M., and Mattoso, L.H.C. (2011a). Sugarcane bagasse whiskers: Extraction and characterizations. Industrial Crops and Products, 33(63), 66. 
Teixeira, E.M, Lotti, C., Corrêa, A.C., Teodoro, K.B.R., Marconcini, J.M., and Mattoso, L.H.M. (2011b). Thermoplastic corn starch reinforced with cotton cellulose nanofibers. Journal of Applied Polymer Science, 120(4), 2428-2433.

Ticoalu, A., Aravinthan, T., and Cardona, F. (2013). A review of the characteristics of gomuti fiber and its composites with thermoset resins. Journal of Reinforced Plastics and Composites, 32(2), 124-136.

Turbak, A.F., Snyder, F.W., and Sandberg, K.R. (1983). Microfibrillated cellulose, a new cellulose product: properties, uses, and commercial potential. Journal of Applied Polymer Science: Applied Polymer Symposium, 37(9), 815-827.

Volk, N., He, R., and Magniez, K. 2015. Enhanced homogeneity and interfacial compatibility in melt-extruded cellulose nano-fibers reinforced polyethylene via surface adsorption of poly(ethylene glycol)-block-poly(ethylene) amphiphiles. European Polymer Journal, 72, 270-281.

Wilhelm, H.M., Sierakowski, M.R., Souza, G.P., and Wypych, F. (2003). Starch films reinforced with mineral clay. Carbohydrate Polymers, 52(2), 101-10.

Wu, Q., Henriksson, M., Liu, X., and Berglund, L.A. (2007). A high strength nanocomposite based on microcrystalline cellulose and polyurethane. Biomacromolecules, 8(12), 3687-3692.

Xiao, S., Gao, R., Gao, L., and Li. (2016). Poly(vinyl alcohol) films reinforced with nanofibrillated cellulose (NFC) isolated from corn husk by high intensity ultrasonication. Carbohydrate Polymers, 136, 1027-1034.

Xiu, M.Z., Zhang, Q.B., Puppala, H.L., Colvin, V.L., and Alvarez, P.J.J. (2012). Negligible particle-specific antibacterial activity of silver nanoparticles. Nano Letters, 12(8), 4271-4275.

Yang, S., Tang, Y., Wang, J., Kong, F., and Zhang, J. (2014). Surface treatment of cellulosic paper with starch-based composites reinforced with nanocrystalline cellulose. Industrial and Engineering Chemistry Research, 53(36), 13980-13988.

Zhou, Y.M., Fu, S.Y., Zheng, L.M., and Zhan, H.Y. (2012). Effect of nanocellulose isolation techniques on the formation of reinforced poly(vinyl alcohol) nanocomposite films. Express Polymer Letters, 6(10), 794-804.

Zuluaga, R., Putaux, J., Restrepo, A., Mondragon, I., and Gañán, P. (2007). Cellulose microfibrils from banana farming residues: isolation and characterization. Cellulose, 14(6), 585-592. 
$\Longrightarrow$ Taylor \& Francis Taylor \& Francis Group http://taylorandfrancis.com 